\title{
Structural Characterization \\ of Phosphatidyl-myo-Inositol Mannosides \\ from Mycobacterium bovis Bacillus Calmette \\ Gúerin by Multiple-Stage Quadrupole Ion-Trap \\ Mass Spectrometry with Electrospray \\ Ionization. II. Monoacyl- and Diacyl-PIMs
}

\author{
Fong-Fu Hsu and John Turk \\ Mass Spectrometry Resource, Division of Endocrinology, Diabetes, Metabolism, and Lipid Research, \\ Department of Internal Medicine, Washington University School of Medicine, St. Louis, Missouri, USA
}

Róisín M. Owens, Elizabeth R. Rhoades, and David G. Russell
Department of Microbiology and Immunology, Cornell University, Ithaca, New York, USA

\begin{abstract}
The multiple-stage ion-trap mass spectrometric approaches towards to the structural characterization of the monoacyl-PIM (triacylated PIM) and the diacyl-PIM (tetracylated PIM), namely, the PIM (diacylated PIM) consisting of one or two additional fatty acid substituents attached to the glycoside, respectively, were described. While the assignment and confirmation of the fatty acid substituents on the glycerol backbone can be easily achieved by the methods described in the previous article, the identity of the glycoside moiety and its acylation state can be determined by the observation of a prominent acylglycoside ion arising from cleavage of the diacylglycerol moiety ([M - $\mathrm{H}-$ diacylglycerol $]^{-}$) in the $\mathrm{MS}^{2}$-spectra of monoacyl-PIM and diacyl-PIM. The distinction of the fatty acid substituents on the 2-O-mannoside (i.e., $\mathrm{R}_{3} \mathrm{CO}_{2} \mathrm{H}$ ) from that on the inositol (i.e., $\mathrm{R}_{4} \mathrm{CO}_{2} \mathrm{H}$ ) is based on the findings that the $\mathrm{MS}^{3}$-spectrum of $\left[\mathrm{M}-\mathrm{H}\right.$ - diacylglycerol] ${ }^{-}$contains a prominent ion arising from further loss of the fatty acid at the 2-O-mannoside (i.e., the $[\mathrm{M}-\mathrm{H}$ - diacylglycerol $\left.-\mathrm{R}_{3} \mathrm{CO}_{2} \mathrm{H}\right]^{-}$ion), while the ion arising from loss of the fatty acid substituent at the inositol (i.e., the $\left[\mathrm{M}-\mathrm{H}-\text { diacylglycerol }-\mathrm{R}_{4} \mathrm{CO}_{2} \mathrm{H}\right]^{-}$ion) is of low abundance. The fatty acyl moiety on the inositol can also be identified by the product-ion spectrum from $\mathrm{MS}^{4}$ of the $[\mathrm{M}-\mathrm{H}$ - diacylglycerol $\left.-\mathrm{R}_{3} \mathrm{CO}_{2} \mathrm{H}\right]^{-}$ion, which gives rise to a prominent ion corresponding to loss of $\mathrm{R}_{4} \mathrm{CO}_{2} \mathrm{H}$. An [M - H - acylmannose $]^{-}$ion was also observed in the $\mathrm{MS}^{2}$-spectra and, thus, the identity of the fatty acid substituent attached to 2-O-mannoside can be confirmed. The combined information obtained from the multiple-stage product-ion spectra from $\mathrm{MS}^{2}, \mathrm{MS}^{3}$, and $\mathrm{MS}^{4}$ permit the assignment of the complex structures of monoacyl-PIMs and diacyl-PIMs in a mixture isolated from M. bovis Bacillus Calmette Guérin. (J Am Soc Mass Spectrom 2007, 18, 479-492) (C) 2007 American Society for Mass Spectrometry
\end{abstract}

A lthough ion-trap tandem mass spectrometry with ESI for structural characterization of complex structures of acyl-PIM $\mathrm{M}_{2}$ was recently reported [1], structural detail revealed by multiple-stage ion-trap tandem mass spectrometry has not been described previously.

In the first part of this report, we described the IT multiple-stage mass spectrometric approaches for characterization of PI and PIM molecules from a lipid extract from $M$. bovis BCG [2]. In this subsequent report,

Published online November 30, 2006

Address reprint requests to Dr. F.-F. Hsu, Box 8127, Washington University School of Medicine, 660 S. Euclid, St. Louis, MO 63110. E-mail: fhsu@im. wustl.edu we will describe the structural determination of the monoacyl- and diacyl PIMs in the extract, using the same mass spectrometric approaches. The assignment of the fatty acid substituents attached to the glycosides of monoacyl-PIM and of diacyl-PIM is based on the understanding that the fatty acyl moieties are connected to the O-6 position of the 2-O-linked Man $p$ and to the $\mathrm{O}-3$ position of the myo-inositol, respectively, based on the previous studies using NMR [3-8].

\section{Materials and Methods}

The isolation of PIMs from M. bovis Bacillus Calmette Guérin (BCG) and the IT multiple-stage mass spectrometry for structural characterization were described in 


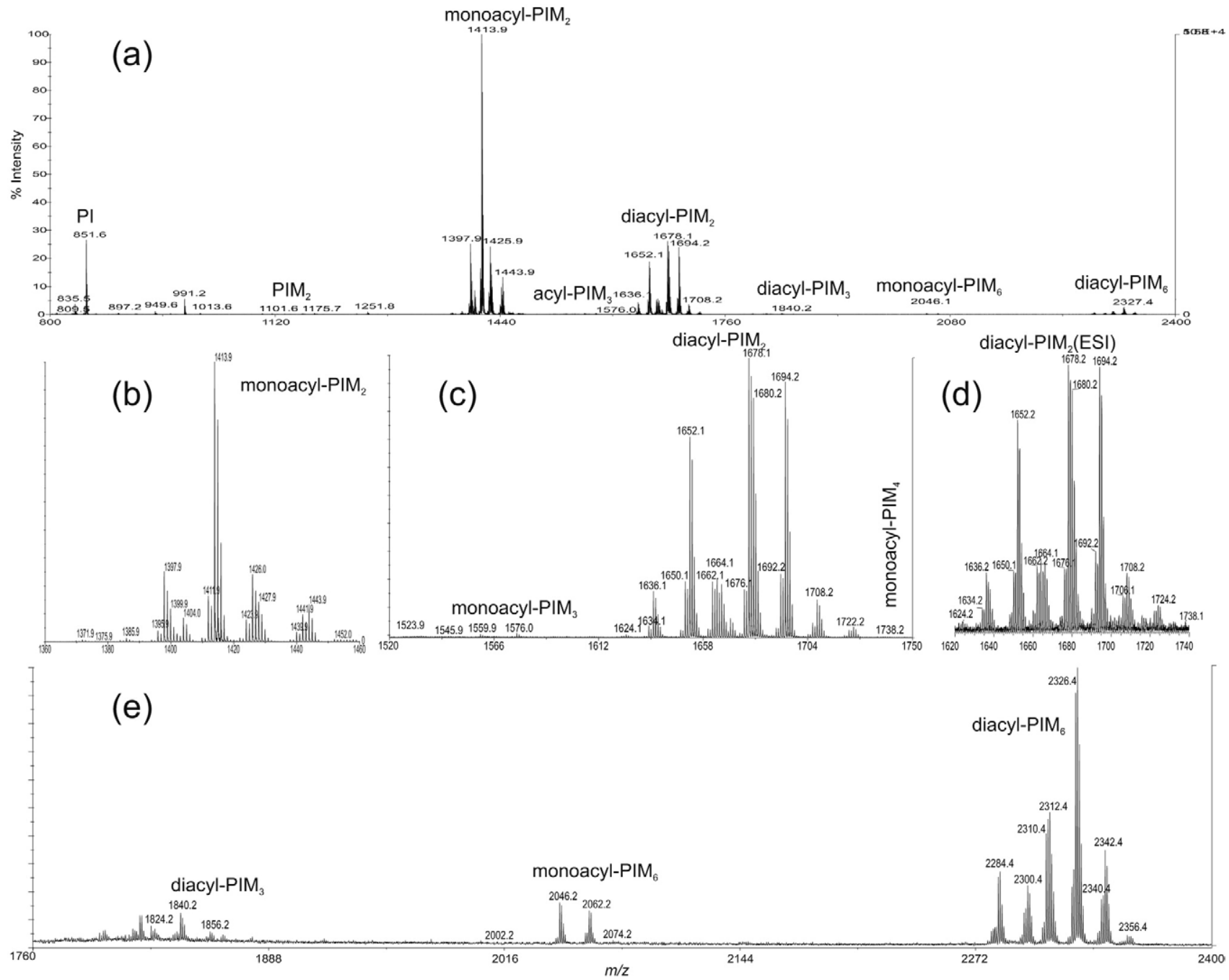

Figure 1. The MALDI-TOF mass spectrum of the complex lipid extract from M. bovis BCG (a), and the separate mass spectra that represent monoacyl-PIM $\mathrm{P}_{2} \mathrm{~s}(\mathrm{~b})$, monoacyl-PIM $_{3} \mathrm{~s}$ and diacyl-PIM $\mathrm{PM}_{2} \mathrm{~s}$ ), and diacyl-PIM $\mathrm{P}_{3} \mathrm{~s}$, monoacyl-PIM $_{6} \mathrm{~s}$ and diacyl-PIM $\mathrm{P}_{6} \mathrm{~s}(\mathbf{e})$. The profile of the high-resolution ESI mass spectrum of diacyl-PIM $\mathrm{P}_{2} \mathrm{~s}$ as shown in (d) is identical to that shown in (c).

the previous article [2]. The abbreviations and nomenclatures described earlier were also used [2].

\section{Results and Discussion}

Figure 1a shows the negative-ion MALDI-TOF mass spectrum of the PIMs from M. bovis BCG obtained in the reflectron and delayed extraction mode. The homologous ions were seen for all the PIMs, including monoacyl-PIM $_{2}$ (Figure 1b), diacyl-PIM ${ }_{2}$ (Figure 1c), diacyl-PIM ${ }_{3}$, monoacyl-PIM ${ }_{6}$, and diacyl-PIM 6 (Figure 1e). The ESI mass spectrum of the $[\mathrm{M}-\mathrm{H}]^{-}$ions of diacyl-PIM $\mathrm{P}_{2}$ acquired by an IT instrument in a highresolution scan mode (Figure 1d) is similar to the spectrum shown in Figure 1c. However, the sensitivity seen in the MALDI-TOF spectrum is at least 10 times greater, indicating that MALDI-TOF method may be suitable for profiling the molecular species of PIMs, while the multiple-stage IT mass spectrometry of the $[\mathrm{M}-\mathrm{H}]^{-}$ ions desorbed by ESI, as described below, is readily applicable for structural identification of the complex structures of PIMs (Table 1).

\section{Characterization of Monoacyl-PIMs}

The $[\mathrm{M}-\mathrm{H}]^{-}$ions belong to the monoacyl-PIM ${ }_{2}$ monoacyl-PIM $_{3}$, monoacyl-PIM ${ }_{4}$, and monoacyl-PIM 6 in the monoacyl-PIM (triacylated PIM) family were observed (Table 1).

Monoacyl-PIM ${ }_{2}$. Among all of the PIMs isolated from M. bovis BCG, the subclass of monoacyl-PIM ${ }_{2}$ was the most abundant, while the ion at $\mathrm{m} / \mathrm{z} 1413$ was the most prominent in the family (Figure 1a, b). As shown in Figure 2a, the IT product-ion spectrum from $\mathrm{MS}^{2}$ of the $\mathrm{m} / \mathrm{z} 1413$ ion is dominated by the ions at $\mathrm{m} / \mathrm{z} 1157$ and 1115 , arising from losses of the 16:0- and 19:0-fatty acid substituents, respectively. The ion at $m / z 1157$ is more 
Table 1. The composition of monoacyl- and diacyl-PIMs from M. bovis BCG

\begin{tabular}{|c|c|c|c|c|c|}
\hline$[\mathrm{M}-\mathrm{H}]^{-}$ & Structure & {$[\mathrm{M}-\mathrm{H}]^{-}$} & Structure & {$[\mathrm{M}-\mathrm{H}]^{-}$} & Structure \\
\hline 1369.8 & $\begin{array}{l}\text { 16:0-(16:0/16:1)-PIM } \\
\text { 14:0-(16:0/18:1)-PIM } \\
\text { 18:0-(16:1/14:0)-PIM } \\
\end{array}$ & 1634.1 & $\begin{array}{l}(16: 0,16: 1)(18: 1 / 16: 0)-\mathrm{PIM}_{2} \\
(16: 0,16: 0)(18: 1 / 16: 1)-\mathrm{PIM}_{2} \\
(16: 0,16: 0)(18: 1 / 16: 0)-\mathrm{PIM}_{2}\end{array}$ & $\begin{array}{l}1824.2 \\
1840.2\end{array}$ & $\begin{array}{l}(16: 0,18: 1)-(18: 1 / 16: 0)-\mathrm{PIM}_{3} \\
(16: 0,18: 1)-(19: 0 / 16: 0)-\mathrm{PIM}_{3} \\
(16: 0,19: 0)-(18: 1 / 16: 0)-\mathrm{PIM}_{3}\end{array}$ \\
\hline 1371.9 & 16:0-(16:0/16:0)-PIM & 1650.1 & $(16: 0,16: 1)(19: 0 / 16: 0)-\mathrm{PIM}_{2}$ & 1856.2 & $(16: 0,19: 0)-(19: 0 / 16: 0)-\mathrm{PIM}_{3}$ \\
\hline 1395.9 & $\begin{array}{l}\text { 16:0-(18:1/16:1)-PIM } \\
\text { 16:1-(18:1/16:0)-PIM } \\
2\end{array}$ & & $\begin{array}{l}(16: 0,16: 0)(19: 0 / 16: 1)-\mathrm{PIM}_{2} \\
(16: 0,16: 0)(18: 1 / 17: 0)-\mathrm{PIM}_{2}\end{array}$ & 2284.3 & $(16: 0,16: 0)-(18: 1 / 16: 0)-\mathrm{PIM}_{6}$ \\
\hline & 16:0-(18:2/16:0)-PIM & & $(16: 0,16: 0)(19: 1 / 16: 0)-\mathrm{PIM}_{2}$ & 2298.3 & $(16: 0,16: 1)-(19: 0 / 16: 0)-\mathrm{PIM}_{6}$ \\
\hline 1397.9 & $\begin{array}{l}\text { 16:0-(18:1/16:0)-PIM } \\
\text { 18:0-(16:0/16:1)-PIM }\end{array}$ & 1652.1 & $\begin{array}{l}(16: 0,16: 0)(19: 0 / 16: 0)-\mathrm{PIM}_{2} \\
(16: 0,17: 0)(18: 0 / 16: 0)-\mathrm{PIM}_{2}\end{array}$ & $\begin{array}{l}2300.3 \\
2310.3\end{array}$ & $\begin{array}{l}(16: 0,16: 0)-(19: 0 / 16: 0)-\mathrm{PIM}_{6} \\
(16: 0,18: 1)-(18: 1 / 16: 0)-\mathrm{PIM}_{6}\end{array}$ \\
\hline 1399.9 & $16: 0-(18: 0 / 16: 0)-\mathrm{PIM}_{2}$ & 1662.1 & $(16: 0,18: 1)(18: 1 / 16: 0)-\mathrm{PIM}_{2}$ & 2312.3 & $(16: 0,18: 0)-(18: 1 / 16: 0)-P_{1 M}$ \\
\hline 1411.9 & $\begin{array}{l}\text { 16:0-(19:0/16:1)-PIM } \\
\text { 16:1-(19:0/16:0)-PIM } \\
\text { 16:0-(19:1/16:0)-PIM } \\
\text { 17:0-(18:1/16:0)-PIM }\end{array}$ & 1664.1 & $\begin{array}{l}(16: 0,18: 0)(18: 1 / 16: 0)-\mathrm{PIM}_{2} \\
(16: 0,17: 1)(19: 0 / 16: 0)-\mathrm{PIM}_{2} \\
(16: 0,16: 0)(18: 1 / 18: 0)-\mathrm{PIM}_{2} \\
(16: 0,18: 1)(19: 0 / 16: 1)-\mathrm{PIM}_{2}\end{array}$ & $\begin{array}{l}2326.4 \\
2328.4 \\
2340.4 \\
2342.4\end{array}$ & $\begin{array}{l}(16: 0,18: 1)-(19: 0 / 16: 0)-\mathrm{PIM}_{6} \\
(16: 0,18: 0)-(19: 0 / 16: 0)-\mathrm{PIM}_{6} \\
(17: 0,18: 1)-(19: 0 / 16: 0)-\mathrm{PIM}_{6} \\
(16: 0,19: 0)-(19: 0 / 16: 0)-\mathrm{PIM}_{6}\end{array}$ \\
\hline 1413.9 & 16:0-(19:0/16:0)-PIM 2 & & $(16: 1,18: 1)(19: 0 / 16: 0)-\mathrm{PIM}_{2}$ & 2354.4 & $(18: 0,18: 1)-(19: 0 / 16: 0)-\mathrm{PIM}_{6}$ \\
\hline 1425.9 & 17:0-(19:0/16:1)-PIM 2 & & $(16: 0,19: 0)(18: 1 / 16: 1)-\mathrm{PIM}_{2}$ & 2356.4 & $(18: 0,18: 0)-(19: 0 / 16: 0)-\mathrm{PIM}_{6}$ \\
\hline 1427.9 & $\begin{array}{l}\text { 17:0-(19:0/16:0)-PIM } \\
\text { 16:0-(19:0/17:0)-PIM }\end{array}$ & & $\begin{array}{l}(16: 0,18: 1)(19: 1 / 16: 0)-\mathrm{PIM}_{2} \\
(17: 0,18: 1)(18: 1 / 16: 1)-\mathrm{PIM}_{2}\end{array}$ & & \\
\hline 1441.9 & $\begin{array}{l}\text { 18:0-(19:0/16:0)-PIM } \\
\text { 16:0-(19:0/18:0)-PIM } \\
\text { 17:0-(19:0/17:0)-PIM } \\
\text { PII }\end{array}$ & 1678.1 & $\begin{array}{l}(16: 0,18: 1)(18: 1 / 17: 0)-\mathrm{PIM}_{2} \\
(16: 0,18: 1)(19: 0 / 16: 0)-\mathrm{PIM}_{2} \\
(16: 0,19: 0)(18: 1 / 16: 0)-\mathrm{PIM}_{2}\end{array}$ & & \\
\hline 1455.9 & $\begin{array}{l}\text { 19:0-(19:0/16:0)-PIM } \\
\text { 18:0-(19:0/17:0)-PIM }\end{array}$ & $\begin{array}{l}1680.2 \\
1692.2\end{array}$ & $\begin{array}{l}(16: 0,18: 0)(19: 0 / 16: 0)-\mathrm{PIM}_{2} \\
(16: 0,19: 0)(18: 0 / 16: 0)-\mathrm{PIM}_{2} \\
(17: 0,18: 1)(19: 0 / 16: 0)-\mathrm{PIM}_{2}\end{array}$ & & \\
\hline 1557.9 & $\begin{array}{l}\text { 16:0-(18:1/16:1)-PIM } \\
\text { 16:1-(18:1/16:0)-PIM }\end{array}$ & & $\begin{array}{l}(16: 0,19: 1)(19: 0 / 16: 0)-\mathrm{PIM}_{2} \\
(16: 1,19: 0)(19: 0 / 16: 0)-\mathrm{PIM}_{2}\end{array}$ & & \\
\hline 1559.9 & 16:0-(18:1/16:0)-PIM 3 & & $(16: 0,19: 0)(19: 1 / 16: 0)-\mathrm{PIM}_{2}$ & & \\
\hline 1573.9 & $\begin{array}{l}\text { 16:0-(19:1/16:0)-PIM } \\
\text { 16:0-(19:0/16:1)-PIM } \\
\text { 16:0-(18:1/17:0)-PIM } \\
\text { 17:0-(18:1/16:0)-PIM } \\
\text { 16:1-(19:0/16:0)-PIM } \\
\text { PIM }\end{array}$ & $\begin{array}{l}1694.2 \\
1704.2\end{array}$ & $\begin{array}{l}(16: 0,19: 0)(19: 0 / 16: 0)-\mathrm{PIM}_{2} \\
(16: 0,18: 1)(19: 0 / 18: 1)-\mathrm{PIM}_{2} \\
(16: 0,19: 0)(18: 1 / 18: 1)-\mathrm{PIM}_{2} \\
(18: 0,18: 1)(19: 0 / 16: 1)-\mathrm{PIM}_{2} \\
(18: 0,19: 0)(18: 1 / 16: 1)-\mathrm{PIM}_{2}\end{array}$ & & \\
\hline 1575.9 & 16:0-(19:0/16:0)-PIM 3 & & $\begin{array}{l}(18: 1,18: 1)(19: 0 / 16: 0)-\mathrm{PIM}_{2} \\
(16: 0,20: 1)(19: 0 / 16: 1)-\mathrm{PIM}_{2}\end{array}$ & & \\
\hline 1722 & 16:0-(18:1/16:0)-PIM 4 & 1706.2 & $(18: 0,18: 1)(19: 0 / 16: 0)-\mathrm{PIM}_{2}$ & & \\
\hline 1738 & 16:0-(19:0/16:0)-PIM 4 & & $\begin{array}{l}(18: 0,19: 0)(18: 1 / 16: 0)-\mathrm{PIM}_{2} \\
(18: 0,19: 0)(18: 0 / 16: 1)-\mathrm{PIM}_{2}\end{array}$ & & \\
\hline 2020.1 & 16:0-(16:0/16:0)-PIM & & $(18: 0,18: 0)(18: 1 / 17: 0)-\mathrm{PIM}_{2}$ & & \\
\hline 2046.1 & 16:0-(18:1/16:0)-PIM & 1708.2 & $(18: 0,18: 0)(19: 0 / 16: 0)-\mathrm{PIM}_{2}$ & & \\
\hline 2062.1 & $16: 0-(19: 0 / 16: 0)-\mathrm{PIM}_{6}$ & & $(17: 0,18: 0)(19: 0 / 17: 0)-\mathrm{PIM}_{2}$ & & \\
\hline 2074.1 & 18:0-(18:1/16:0)-PIM & & $(16: 0,18: 0)(19: 0 / 18: 0)-\mathrm{PIM}_{2}$ & & \\
\hline 2090.1 & 18:0-(19:0/16:0)-PIM & 1720.2 & $(18: 1,19: 0)(19: 0 / 16: 0)-\mathrm{PIM}_{2}$ & & \\
\hline 2104.1 & 19:0-(19:0/16:0)-PIM & 1722.2 & $\begin{array}{l}(16: 0,19: 0)(19: 0 / 18: 1)-\mathrm{PIM}_{2} \\
(18: 0,19: 0)(19: 0 / 16: 1)-\mathrm{PIM}_{2} \\
(18: 1,18: 0)(19: 0 / 17: 0)-\mathrm{PIM}_{2} \\
(18: 0,19: 0)(19: 0 / 16: 0)-\mathrm{PIM}_{2} \\
(16: 0,19: 0)(19: 0 / 18: 0)-\mathrm{PIM}_{2}\end{array}$ & & \\
\hline
\end{tabular}

abundant than the ion at $m / z 1115$, indicating that the 16:0- and 19:0-fatty acyl substituents are located at $s n-2$ and $s n-1$ of the glycerol backbone, respectively. The assignment is further examined by the $\mathrm{MS}^{3}$-spectra of the ions at $m / z 1157(1413 \rightarrow 1157$ ) (Figure $2 b$ ) and $m / z$ $1115(1413 \rightarrow 1115)$ (Figure 2c). The former spectrum contains the ions at $m / z 1101(1157$ - 56) and 1083 (1157 $74)$, probably arising from the losses of the glycerol moieties involving a rearrangement process, similar to those observed for PI and PIM [2] and the two ions are nearly of equal abundance. The latter spectrum contains ions at $m / z 1059(1115-56)$ and $m / z 1041$ (1115 - 74) arising from the similar losses of the glycerol moieties.
However, the ion at $\mathrm{m} / \mathrm{z} 1058$ is much more prominent than the ion at $m / z$ 1041. The drastic differences in the profiles of the two spectra indicate that the $\mathrm{MS}^{3}$-spectra of the ions at $m / z 1157(1413$ - 256) and 1059 (1413 298) can be used to distinguish the fatty acid substituent at $s n-2$ from that at $s n-1$. Therefore, the positions of the 16:0-fatty acyl substituent at $s n-2$ and of the 19:0-fatty acid moiety at $s n-1$ can be confirmed.

The ion at $m / z 859$ (Figure 2a) arises from the combined losses of the 16:0- and 19:0-fatty acid moieties and the ion at $m / z 877$ arises from the combined losses of the fatty acyl moiety at $s n-1$ (or $s n-2)$ either as an acid molecule and the fatty acyl substituent at $s n-2$ (or $s n-1$ ) 

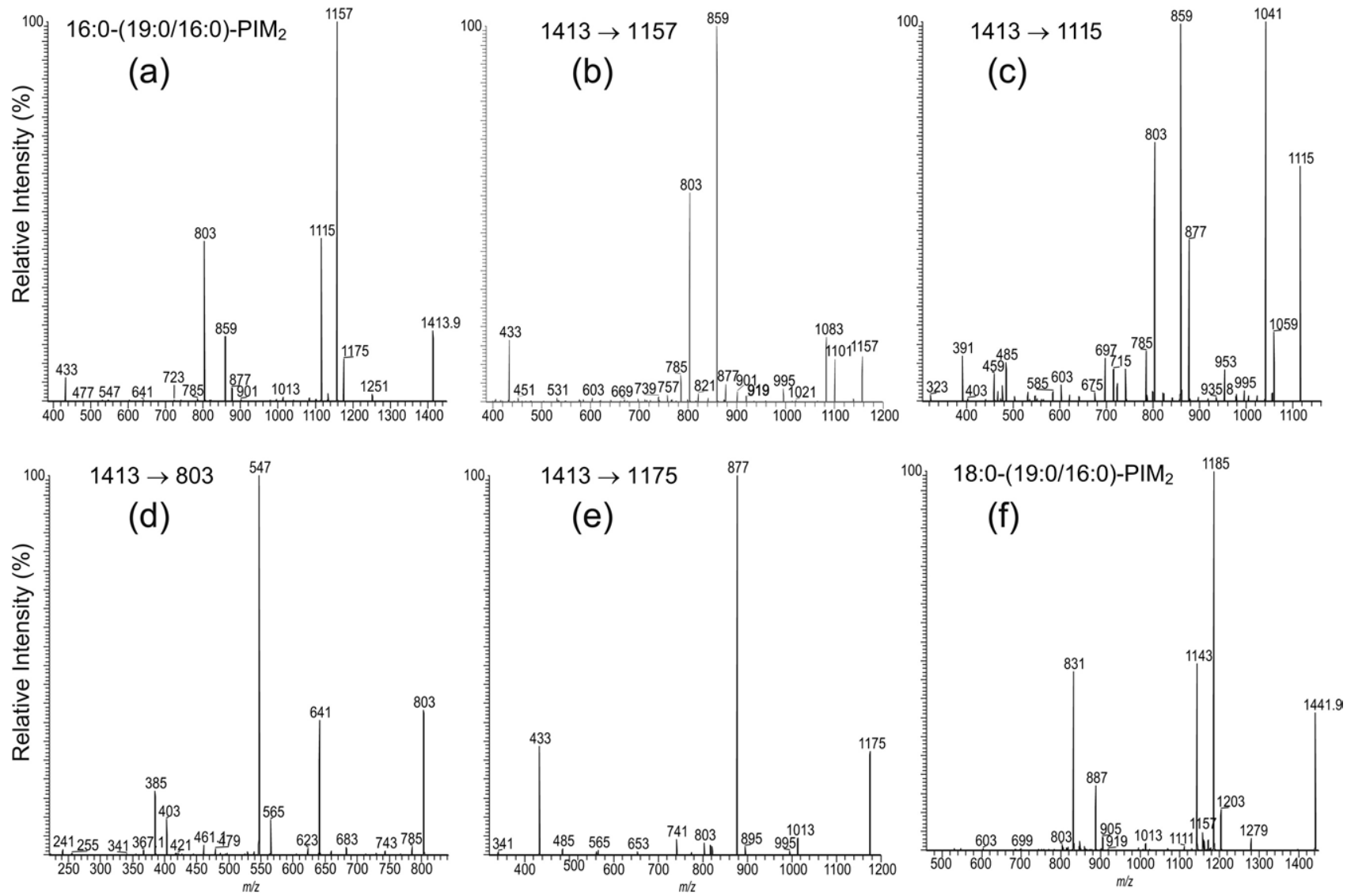

Figure 2. The IT MS ${ }^{2}$ product-ion spectrum of the $[\mathrm{M}-\mathrm{H}]^{-}$ion of $16: 0-(19: 0 / 16: 0)-\mathrm{PIM}_{2}$ at $\mathrm{m} / \mathrm{z}$ 1413.9 (a), and its $\mathrm{MS}^{3}$ product-ion spectra of the ions at $\mathrm{m} / \mathrm{z} 1157(1413 \rightarrow 1157)(\mathbf{b})$, at $\mathrm{m} / \mathrm{z} 1115(1413 \rightarrow$ 1115) (c), at $m / z 803(1413 \rightarrow 803)(\mathbf{d})$, and at $m / z 1175(1413 \rightarrow 1175)(\mathbf{e})$; panel $(\mathbf{f})$ illustrates the IT MS ${ }^{2}$ product-ion spectrum of the homologous ion at $m / z$ 1441.9, arising from 18:0-(19:0/16:0)-PIM . $_{\text {. }}$

or as a ketene molecule. The fragmentation pathways are consistent with the observation of the ions at $m / z 859$ and 877 in the MS $^{3}$-spectra of the ions at $\mathrm{m} / \mathrm{z} 1157$ $(1413 \rightarrow 1157)$ (Figure $2 b)$ and $1115(1413 \rightarrow 1115)$ (Figure 2c), which undergo further dissociation to eliminate the remaining fatty acid substituent at the glycerol backbone. The ion at $\mathrm{m} / \mathrm{z} 877$ in Figure $2 \mathrm{c}$ is more abundant than that in Figure 2b, suggesting that further loss of the 16:0-fatty acyl moiety at $s n-2$ as a ketene from the precursor $\left[\mathrm{M}-\mathrm{H}-\mathrm{R}_{1} \mathrm{CO}_{2} \mathrm{H}\right]^{-}$ion (i.e., $m / z$ 1115) may be more favorable than further loss of the 19:0-fatty acyl ketene at $s n-1$ from the $\left[\mathrm{M}-\mathrm{H}-\mathrm{R}_{2} \mathrm{CO}_{2} \mathrm{H}\right]^{-}$ion (i.e., $\mathrm{m} / \mathrm{z}$ 1157). These differences between the two spectra may also provide structural information for locating the fatty acyl substituents at the glycerol backbone [2].

A 16:0-fatty acyl substituent attached to the glycoside is recognized by the presence of the ion at $\mathrm{m} / \mathrm{z} 803$ in Figure 2a, b, and c. This ion arises from loss of the diacylglycerol and is $238 \mathrm{Da}$ higher than that of the analogous ion at $m / z 565$ observed for 19:0/16:0-PIM [2]. The presence of 16:0-fatty acyl substituent at the glycoside is also consistent with the presence of the ions at $m / z 1251(1413-162)$ and $1013(1413-400)$, arising from losses of a mannosyl (probably mannose 2) and a palmitoylmannosyl (i.e., mannose 1 with an O-6 16:0fatty acyl group) residues, respectively, along with the ion at $m / z 723$ arising from loss of 19:0/16:0-PI (Scheme 1) [2]. The presence of the ion at $m / z 1013$ suggests that the 16:0-fatty acyl substituent is located on the mannosyl residue rather than on the inositol moiety.

Further dissociation of the ion at $\mathrm{m} / \mathrm{z} 803(1413 \rightarrow$ 803) gives the ions at $\mathrm{m} / \mathrm{z} 547$ and 565, arising from losses of the 16:0-fatty acyl substituent as an acid and as a ketene molecules, respectively (Figure $2 \mathrm{~d}$ ). The spectrum also contains the ions at $m / z 641(803-162)$ and $623(803-180)$, arising from loss of a mannosyl moiety, along with the ion at $\mathrm{m} / \mathrm{z} 403(803-400)$, corresponding to loss of a palmitoylmannosyl residue as described earlier. The MS ${ }^{4}$ product-ion spectra of the ions at $\mathrm{m} / \mathrm{z}$ 803 originated from $m / z 1115$ (i.e., $1413 \rightarrow 1115 \rightarrow 803$ ) and from $m / z 1157$ (i.e., $1413 \rightarrow 1157 \rightarrow 803$ ) (data not shown) are also identical to that shown in Figure 2d. The presence of the $\mathrm{m} / \mathrm{z} 803$ ion in the MS ${ }^{3}$-spectra of $\mathrm{m} / \mathrm{z} 1157$ (Figure $2 \mathrm{~b}$ ) and $\mathrm{m} / \mathrm{z} 1115$ (Figure 2c) is consistent with the fact that a $16: 0$-fatty acyl moiety is attached to mannose 1.

The IT $\mathrm{MS}^{3}$-spectrum of $\mathrm{m} / \mathrm{z} 1157$ (Figure 2b) is dominated by the ion at $m / z 859$ arising from loss of the 19:0-fatty acyl substituent at $s n-1$, while the ion at $\mathrm{m} / \mathrm{z}$ 


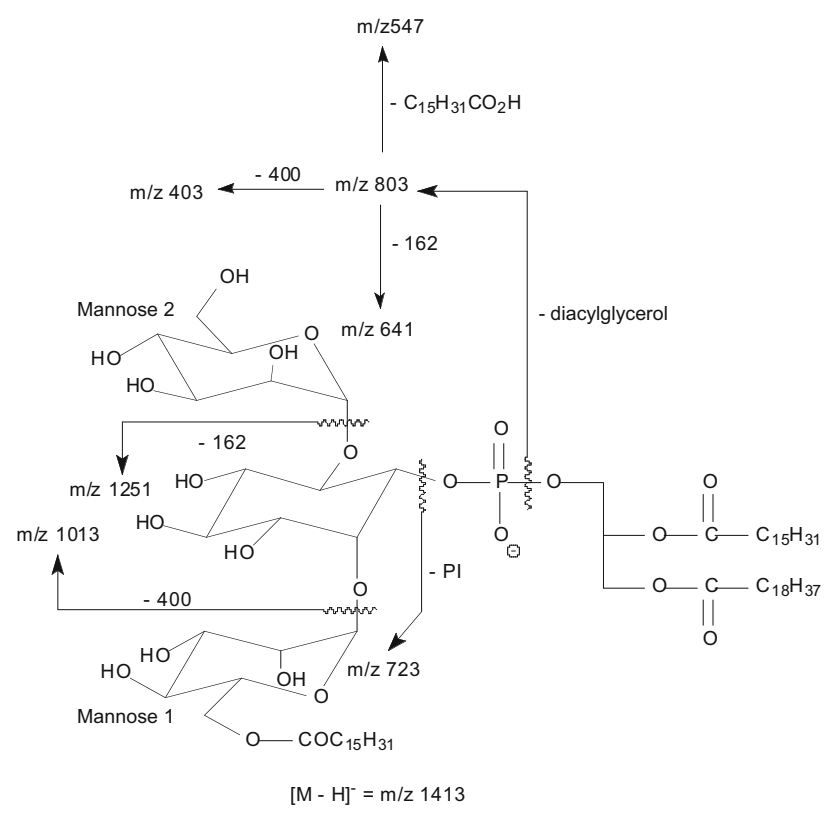

Scheme 1. The fragmentation pathways proposed for 16:0-(19: 0/16:0)-PIM

901 corresponding to loss of the 16:0-fatty acyl substituent attached to mannose 1 is of low abundance. The results indicate that loss of the fatty acyl moiety at the mannosyl residue (assigned as mannose 1) is less favorable than that at $s n-1$ (or $s n-2$ ) of the glycerol backbone. This finding is also supported by the IT MS ${ }^{3}$-spectrum of the $m / z 1175$ ion $(1413 \rightarrow 1175)$ (Figure 2e), which is equivalent to a $[\mathrm{M}-\mathrm{H}]^{-}$ion of 16:0-(19:0/0)- $\mathrm{PIM}_{2}$, arising from primary loss of the 16:0-fatty acyl substituent at $s n-2$ as a ketene. The spectrum is dominated by the ion at $\mathrm{m} / \mathrm{z} 877$ corresponding to loss of the 19:0-fatty acid at $s n-1$ and the ion expected at $\mathrm{m} / \mathrm{z} 919$ corresponding to loss of the 16:0-fatty acid substituent at mannose 1 (i.e., loss of $\mathrm{R}_{3} \mathrm{CO}_{2} \mathrm{H}$ ) is not present [2]. This preferential loss of the fatty acid substituents at the glycerol backbone over that at the glycosyl moiety readily provides information to distinguish the fatty acyl substituents at glycerol backbone from that at mannose 1 and from that at the inositol (discuss later). The spectrum is also readily distinguishable from that arising from (19:0/16:0)-PIM ${ }_{2}$ [2], demonstrating the utility of IT tandem mass spectrometry in the differentiation of positional isomers such as (19:0/16:0)-PIM $\mathrm{PI}_{2}$ and 16:0-(19:0/0)-PIM .

The IT MS²-spectrum of the ion at $m / z 1441$ (Figure 2f) is similar to that observed for the ion at $\mathrm{m} / \mathrm{z} 1413$ (Figure 2a) and the analogous ion arising from elimination of the diacylglycerol is seen at $\mathrm{m} / \mathrm{z} 831$, indicating that the molecule consists of a 18:0-fatty acyl substituent attached to mannose 1 . The ions at $\mathrm{m} / \mathrm{z} 1185$ and 1143 , arising from losses of the 16:0- and 19:0-fatty acyl substituents at $s n-2$ and $s n-1$, respectively, are prominent. However, the ion at $\mathrm{m} / \mathrm{z} 1157$ corresponding to loss of the 18:0-fatty acyl moiety is of low abundance, consistent with the notion that loss of the fatty acid on the glycosyl residue is less favorable than those attached to the glycerol backbone.

Nearly all of the acyl-PIM ${ }_{2}$ analyzed consists of more than one isomeric structure (Table 1). The complexity of the structures of the ions is shown by the ion at $\mathrm{m} / \mathrm{z}$ 1411, which gives an $\mathrm{MS}^{2}$-spectrum (Figure 3a) that contains ions at $\mathrm{m} / \mathrm{z} 1157,1155,1141,1129,1115$, and 1113 , reflecting the losses of the 16:1-, 16:0-, 17:0-, 18:1-, 19:1-, and 19:0-fatty acid moieties, respectively. The ions arising from losses of the various diacylglycerol moieties were observed at $m / z$ 817, 803, and 801, indicating the presence of the molecular species consisting of a 17:0-, 16:0-, and a 16:1-fatty acyl substituents attached to mannose 1 . The structures of the molecules are further unveiled by IT $\mathrm{MS}^{3}$ spectrometry.

Further dissociation of the $\mathrm{m} / \mathrm{z} 1157$ ion $(1411 \rightarrow$ 1157) (Figure 3b), which originates from a primary loss of a 16:1-fatty acyl substituent, gives rise to the ions at $\mathrm{m} / \mathrm{z} 1101$ (1157 - 56) and 1083 (1157 - 74), by various losses of the glycerol residues as described earlier. The spectrum is nearly identical to that shown in Figure $2 b$, indicating that the $\mathrm{m} / \mathrm{z} 1157(1411-254)$ ion arises from $\mathrm{m} / \mathrm{z} 1411$ by loss of the 16:1-fatty acid moiety at $s n-2$, and thus the 19:0- and the 16:1-fatty acyl substituents can be assigned at $s n-1$ and $s n-2$, respectively, while the assignment of the 16:0-fatty acid moiety at mannose 1 is confirmed by the $\mathrm{MS}^{3}$-spectrum of the ion at $\mathrm{m} / \mathrm{z} 803$ (not shown), which is identical to that shown in Figure 2d.

In contrast, the profile of the ions at $m / z 1039$ (1113 74) and 1057 (1113 - 56) in the $\mathrm{MS}^{3}$-spectrum of the ion at $m / z 1113\left(1411-\mathrm{C}_{18} \mathrm{H}_{37} \mathrm{CO}_{2} \mathrm{H}\right)(1411 \rightarrow 1113)$ (Figure $3 c)$ is similar to that seen in Figure 2c, suggesting that the ion at $m / z 1113$ arises from the ion at $m / z 1411$ by loss of the 19:0-fatty acid at $s n-1$. The spectrum also contains ions at $\mathrm{m} / \mathrm{z} 859$ and 877, arising from losses of the 16:1-fatty acid moiety as acid and as ketene molecules at sn-2, respectively, along with the ion at $\mathrm{m} / \mathrm{z} 803$ that signifies that a 16:0-fatty acyl group is attached to mannose 1 . The results are consistent with the assignment earlier that showed the ion at $m / z 1411$ is mainly a 16:0-(19:0/16:1)-PIM ${ }_{2}$ isomer.

In Figure 3c, ions at $m / z 857$ and 875, corresponding to losses of a 16:0-fatty acid moiety as an acid and as a ketene, respectively, along with the ion at $\mathrm{m} / \mathrm{z} 801$, corresponding to the phospholipoglycoside ion consisting of a 16:1-fatty acyl substituent at mannose 1 are also present. The results indicate that the $m / z 1411$ ion may also consist of a 16:1-(19:0/16:0)-PIM ${ }_{2}$ isomer. This structural assignment is supported by the $\mathrm{MS}^{3}$-spectrum of the ion at $\mathrm{m} / \mathrm{z} 1155\left(1411-\mathrm{C}_{15} \mathrm{H}_{31} \mathrm{CO}_{2} \mathrm{H}\right)(1411 \rightarrow 1155)$ (Figure 3d), arising from primary loss of a 16:0-fatty acid moiety. The profile of the ions at $m / z 1081$ (1155 74) and 1099 (1155 - 56) resembles that of Panel b but differs from that of Panel c, suggesting that the 16:0fatty acid is located at $s n-2$ in the structure of 16:1-(19: 0/16:0)-PIM ${ }_{2}$. The spectrum also contains ions at $\mathrm{m} / \mathrm{z}$ 857, arising from loss of the 19:0-fatty acid substituent at $s n-1$, along with the ion at $\mathrm{m} / \mathrm{z} 801$ reflecting that a 16:1-fatty acyl moiety is attached to mannose 1 and in 

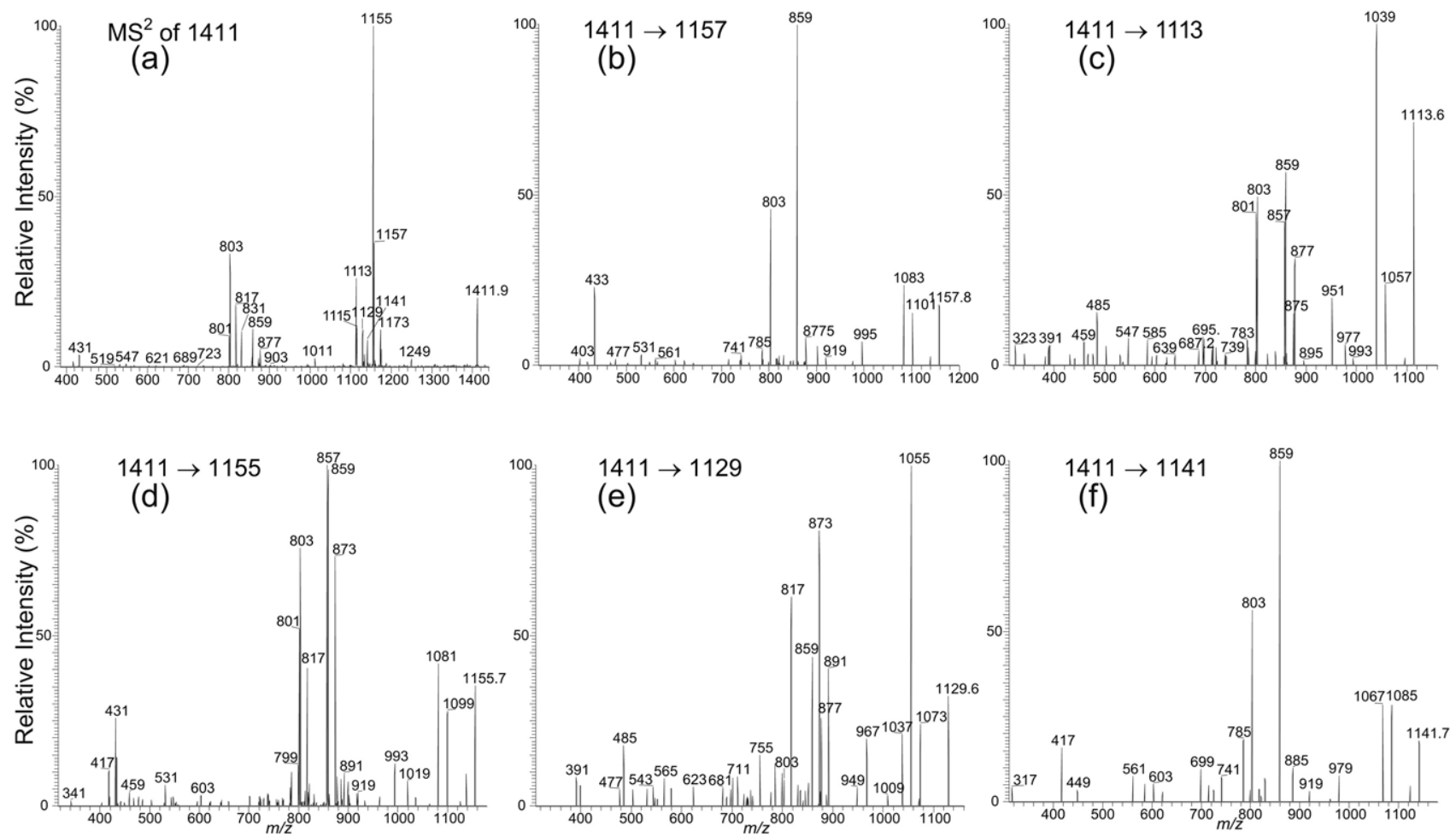

Figure 3. The IT MS ${ }^{2}$ product-ion spectrum of the ion at $\mathrm{m} / \mathrm{z} 1411.9$ (a), and its $\mathrm{MS}^{3}$ product-ion spectra of the ions at $m / z 1157(1411 \rightarrow 1157)(\mathbf{b})$, at $m / z 1113(1411 \rightarrow 1113)(\mathbf{c})$, at $m / z 1155(1411 \rightarrow$ $1155)(\mathbf{d})$, at $m / z 1129(1411 \rightarrow 1129)(\mathbf{e})$, and at $m / z 1141(1411 \rightarrow 1141)(\mathbf{f})$. The product-ion spectra from $\mathrm{MS}^{2}$ and $\mathrm{MS}^{3}$ confirm that the ion at $m / z 1411$ consists of a major 16:0-(19:0/16:1)-PIM 2 structure and several monoacyl-PIM ${ }_{2}$ isomers.

agreement with the assigned 16:1-(19:0/16:0)-PIM ${ }_{2}$ structure.

In the same spectrum (Figure $3 \mathrm{~d}$ ), the ions at $m / z 873$ and 859 corresponding to losses of a 18:1- and a 19:1-fatty acid moieties, respectively, are also prominent. The $m / z 859$ ion is formed concurrently with the prominent ion at $m / z$ 803, arising from a 16:0-(19:1/16: $0)-\mathrm{PIM}_{2}$ isomer, in agreement with the observation of the ion at $m / z 1115$ in Figure 3a, arising from loss of 19:1-fatty acid moiety, while the ions at $m / z 873$ and 817 may arise from a 17:0-18:1/16:0- $\mathrm{PIM}_{2}$ isomer. The assignment of this latter structure is further confirmed by the $\mathrm{MS}^{3}$-spectrum of the $m / z 1129\left(1411-\mathrm{C}_{17} \mathrm{H}_{33} \mathrm{CO}_{2} \mathrm{H}\right)$ $(1411 \rightarrow 1129)$ ion (Figure $3 \mathrm{e})$, which contains the ions at $m / z 1055(1129-74)$ and $1073(1129-56)$ with a pattern similar to that in Figure $3 c$, along with the ions at $\mathrm{m} / \mathrm{z}$ 873 and 891, arising from losses of the 16:0-fatty acid as an acid and as a ketene at sn-2, respectively, while the ion observed at $m / z 817$ signifies that a 17:0-fatty acyl substituent is attached to mannose 1 .

The presence of the ions at $m / z 859$ and 877 (Figure 3e) arising from loss of 17:0-fatty acyl substituent as an acid and as a ketene molecules, respectively, and of the ion at $m / z 803$ that signifies a 16:0-fatty acyl group attached to mannose 1 , indicates that a 16:0-(18:1/17:0)-PIM ${ }_{2}$ structure may also exist. The $\mathrm{MS}^{3}$-spectrum of the $\mathrm{m} / \mathrm{z}$ $1141(1411 \rightarrow 1141)$ ion (Figure 3f), formed from $\mathrm{m} / \mathrm{z}$ 1411 by primary loss of a 17:0-fatty acid, shows that the profile of the ions at $m / z 1067$ (1141 - 74) and 1085 (1141 - 56) is similar to that in Figure 3b, supporting that indeed the 17:0-fatty acyl group is located at $s n-2$, while the prominent ion at $\mathrm{m} / \mathrm{z} 859$ arising from loss of 18:1-fatty acid identifies the fatty acid substituent at $s n-1$, and the ion at $m / z 803$ reveals the attachment of a 16:0-fatty acyl group to mannose 1 as described earlier.

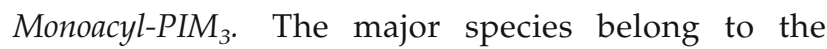
monoacyl-PIM $_{3}$ family was observed at $\mathrm{m} / \mathrm{z} 1575$ (Figure 1a, c), which is $162 \mathrm{Da}$ heavier than the $[\mathrm{M}-\mathrm{H}]^{-}$ ion of 16:0-19:0/16:0-PIM $\mathrm{PI}_{2}$ at $m / z$ 1413, indicating the presence of an additional mannose residue. The IT $\mathrm{MS}^{2}$-spectrum of the ion at $m / z 1575.9$ (Figure 4a) is similar to that observed for 16:0-19:0/16:0-PIM 2 (Figure 2a). The structurally informative ions are seen at $m / z 1319$ and 1337, which arise from losses of the 16:0-fatty acyl substituent at $s n-2$ as an acid and as a ketene, respectively, are more abundant than the ions at $m / z 1277$ and 1295, arising from the analogous losses of the 19:0-fatty acyl substituent at $s n-1$. The ions at $m / z 965$ and 885 arising from losses of a 19:0,16:0-diacylglycerol and a 19:0/16:0-PI moieties, respectively, are 162 Da higher than the analogous ion at $m / z 803$ and 723 observed in

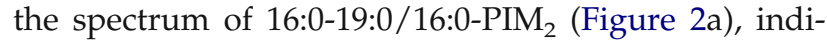
cating that the compound may consist of a 16:0-19:0/ 16:0-PIM $\mathrm{P}_{3}$ structure. The $\mathrm{m} / \mathrm{z} 1251$ ion, probably arising from cleavage of the $\alpha-(1 \rightarrow 6)$ bond (between 

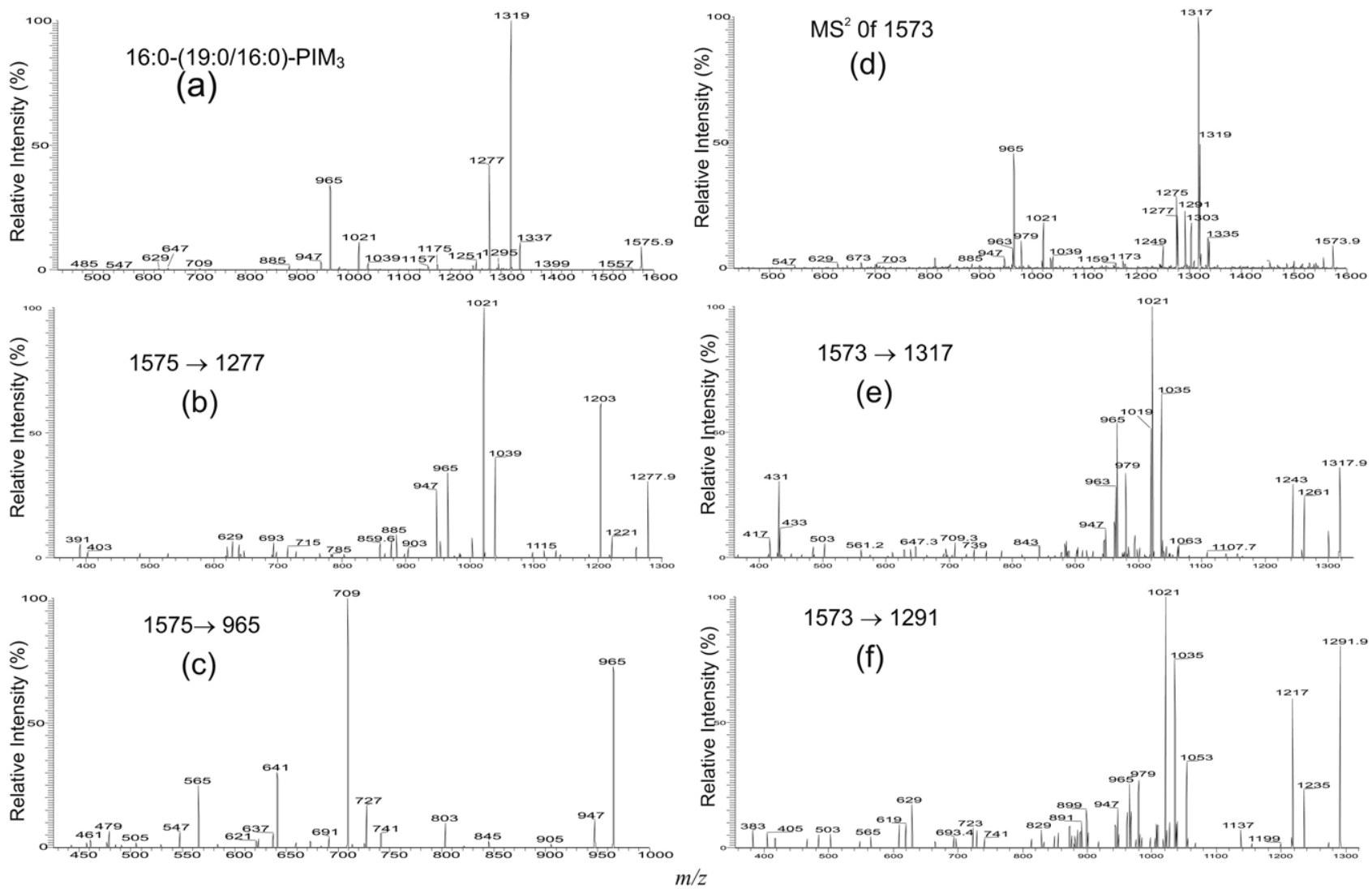

Figure 4. The IT MS ${ }^{2}$ product-ion spectrum of the $[\mathrm{M}-\mathrm{H}]^{-}$ion of 16:0-(19:0/16:0)-PIM $\mathrm{P}_{3}$ at $\mathrm{m} / \mathrm{z}$ 1575.9 (a), and its $\mathrm{MS}^{3}$ product-ion spectra of the ions at $\mathrm{m} / \mathrm{z} 1277(1575 \rightarrow 1277)(\mathbf{b})$, and at $\mathrm{m} / \mathrm{z} 803$ $(1575 \rightarrow 965)(\mathbf{c})$; panel $(\mathbf{d})$ illustrates the $\mathrm{MS}^{2}$ product-ion spectrum of the ion at $\mathrm{m} / \mathrm{z} 1573.9$, which is mainly a 16:0-19:1/16:0-PIM 3 isomer. The MS ${ }^{3}$ product-ion spectra of the ions at $\mathrm{m} / \mathrm{z} 1317(1573 \rightarrow$ 1317) (e), and at $m / z 1291(1573 \rightarrow 1291)(\mathbf{f})$, revealed that isomers with 17:0-18:1/16:0-PIM ${ }_{3}$ 16:1-19:0/16:0-PIM ${ }_{3}, 16: 0-18: 1 / 17: 0-\mathrm{PIM}_{3}$, and 17:0-18:1/16:0-PIM ${ }_{3}$ structures are also present. The assigned structures are further confirmed by the $\mathrm{MS}^{3}$-spectra of the ions at $\mathrm{m} / z 1303(1573 \rightarrow 1303)$, and at $m / z 1275(1573 \rightarrow 1275)$ (shown in Supplementary Material).

6-man $p \alpha-1 \rightarrow$ linked to $0-6$ of the myo-inositol) to eliminate of a dimannosyl residue, is similar to that observed for 16:0-19:0/16:0-PIM 2 (Figure 2a), which eliminates a mannose by the same cleavage (Scheme 1) [2]. The ions arising from loss of the 16:0- (or 19:0) fatty acyl substituent, followed by loss of 19:0- (or 16:0) fatty acyl substituent as an acid or as a ketene molecule were observed at $\mathrm{m} / \mathrm{z} 1021$ (loss of two acids) and 1039 (loss of one acid and one ketene), respectively. The ions that are indicative of a $\mathrm{PIM}_{3}$ structure are observed at $\mathrm{m} / \mathrm{z}$ 1175 (1575 - 238 - 162) and 1157 (1575 - 256 - 162), arising from the various losses of the palmitoylmannosyl moieties.

The assignment of the 19:0- and 16:0-fatty acid substituents at $s n-1$ and $s n-2$ of the glycerol backbone is further confirmed by the IT $\mathrm{MS}^{3}$-spectrum of the ion at $m / z 1319(1575 \rightarrow 1319)$ (shown in Supplementary Material which can be found in the electronic version of this article), which gives the ions at $m / z 1263$ (1319 - 56) and $1245(1319$ - 74) with a profile that indicates that the 16:0-fatty acid substituent is located at $s n$-2. The ions at $m / z 1203(1277-56)$ and $1185(1277-74)$ seen in the
IT $\mathrm{MS}^{3}$-spectrum of the ion at $m / z 1277(1575 \rightarrow 1277)$ (Figure $4 \mathrm{~b}$ ) also confirm that the 19:0-fatty acid substituent is located at $s n-1$. Further dissociation of the ion at $m / z 965(1575 \rightarrow 965)$ (Figure 4c) gives rise to the ions at $m / z 709\left(965-\mathrm{C}_{15} \mathrm{H}_{31} \mathrm{CO}_{2} \mathrm{H}\right)$ and $727\left(965-\mathrm{C}_{14} \mathrm{H}_{29} \mathrm{CH}=\right.$ $\mathrm{CO})$ by loss of the 16:0-fatty acid moiety attached to mannose 1, along with the ion at $m / z 641$ (965 - $162 \times$ 2) by loss of a dimannosyl residue, and the ions at $\mathrm{m} / \mathrm{z}$ 565 (965 - 238 - 162) and 547 (965 - 256 - 162) by losses of the palmitoylmannosyl moieties. The presence of the ions at $m / z 565$ and 547 is consistent with the observation of the ions at $\mathrm{m} / z 1175$ and 1157 in Figure $4 a$, supporting the assignment that a $16: 0$-fatty acyl group $\left(\mathrm{R}_{3} \mathrm{CO}-\right)$ is attached to mannose 1 , rather than to the inositol. The analogous ions were also observed for the ion at $m / z 1559.9$, which represents a 16:0-18:1/16: 0-PIM ${ }_{3}$ structure (data not shown).

Several isomeric structures were observed for the ions at $\mathrm{m} / \mathrm{z} 1573$ and1557 (Table 1). The IT MS ${ }^{2}$-spectrum of the ion at $m / z 1573.9$ (Figure $4 \mathrm{~d}$ ) contains several sets of the ions at $m / z 1317$ and 1335, reflecting the losses of the 16:0-fatty acid substituent as an acid and as a ketene, 
respectively; at $m / z 1303$ and 1321, corresponding to the analogous losses of the 17:0-fatty acid substituent; at $\mathrm{m} / \mathrm{z} 1291$ and 1309, corresponding to the analogous losses of the 18:1-fatty acyl substituent; at $\mathrm{m} / \mathrm{z} 1277$ and 1295 , corresponding to the analogous losses of the 19:1-fatty acyl substituent; at $\mathrm{m} / \mathrm{z} 1275$ and 1293 , corresponding to the analogous losses of the 19:0-fatty acyl substituent. The presence of the 16:0-, 17:0-, and 16:1fatty acyl substituents attached to the glycoside (i.e., mannose 1) is seen by the ions at $m / z 965,979$, and 963 . The presence of the 16:0-19:1/16:0-PIM ${ }_{3}$ structure is reflected by the set of the ions at $m / z 1317,1275$, and 965 , which signify the 16:0-, 19:1-, and 16:0-fatty acyl moieties at $s n-2, s n-1$ and at mannose 1, respectively. The assignment is consistent with the observation of the ion at $\mathrm{m} / \mathrm{z} 1021$, arising from the combined losses of the 16:0-fatty acid at $s n-2$ and the 19:1-fatty acid at $s n-1$, along with the ion at $m / z 1249$, arising from loss of a dimanosyl residue. The assignment of the 16:0-19:1/16: $0-\mathrm{PIM}_{3}$ structure is also supported by the $\mathrm{MS}^{3}$-spectrum of the $\mathrm{m} / \mathrm{z} 1317$ ion $(1573 \rightarrow 1317)$ (Figure 4e), which contains the ions at $m / z 1261(1317-56)$ and 1243 (1317 - 74) that show the pattern indicating that the ion at $\mathrm{m} / \mathrm{z} 1317$ arises from $\mathrm{m} / \mathrm{z} 1573$ due to loss of the 16:0-fatty acid substituent at $s n-2$. The spectrum is also dominated by the ion at $\mathrm{m} / \mathrm{z} 1021$ arising from further loss of the 19:1-fatty acid substituent at sn-1, along with the ion at $\mathrm{m} / \mathrm{z}$ 965, consistent with the assigned structure.

In the same spectrum (Figure $4 \mathrm{e}$ ), the ion pairs at $\mathrm{m} / \mathrm{z}$ $1035(1317-282)$ and 979 , and at $m / z 1019(1317-298)$ and 963 , probably arising from a 17:0-18:1/16:0- $\mathrm{PIM}_{3}$ and a 16:1-19:0/16:0-PIM ${ }_{3}$ structures, respectively, were also observed. The profile of the IT MS ${ }^{3}$-spectrum of the $\mathrm{m} / \mathrm{z} 1277$ ion $(1573 \rightarrow 1277)$ (not shown) is identical to that shown in Figure 4b, suggesting the presence of an isomer comprising a 19:1-fatty acid substituent at sn-1. Because the spectrum also contains a prominent ion at $\mathrm{m} / \mathrm{z} 1021$ reflecting loss of the 16:0-fatty acid substituent at $s n-2$, along with the ion at $m / z 965$ that reflect the attachment of a 16:0-fatty acid substituent to mannose 1 , a 16:0-19:1/16:0-PIM ${ }_{3}$ structure can be confirmed.

Further dissociation of the ion at $\mathrm{m} / \mathrm{z} 1291$ (1573 282) (1573 $\rightarrow 1291$, Figure $4 \mathrm{f}$ ), gives rise to the ions at $\mathrm{m} / z 1217(1291-74)$ and $1235(1291-56)$ with a pattern similar to that in Figure $4 \mathrm{~b}$, supporting that the ion at $\mathrm{m} / \mathrm{z} 1291$ arises from loss of the 18:1-fatty acid substituent at $s n-1$ from $m / z$ 1573. The ions at $m / z 1035$ (1291 256) and 1053 (1291 - 238), arising from further loss of a 16:0-fatty acid substituent as acid and as ketene, respectively, are formed together with the ion at $\mathrm{m} / \mathrm{z}$ 979. These results support the earlier finding that the ion at $\mathrm{m} / \mathrm{z} 1573$ also represents a 17:0-18:1/16:0-PIM ${ }_{3}$ structure. The spectrum is also dominated by the ion at $\mathrm{m} / z 1021(1291-270)$ along with 965, suggesting that a 16:0-18:1/17:0-PIM ${ }_{3}$ isomeric structure may also exist. The presence of this latter isomer is further supported by the IT MS ${ }^{3}$-spectrum of the ion at $\mathrm{m} / z 1303(1573 \rightarrow$ 1303) (shown in Supplementary Material), which shows that the $m / z 1303\left(\left[\mathrm{M}-\mathrm{H}-\mathrm{R}_{2} \mathrm{CO}_{2} \mathrm{H}\right]^{-}\right)$ion also arises from $\mathrm{m} / \mathrm{z} 1573$ via loss of a 17:0-fatty acid at $s n-2$ and gives rise to the ion at $m / z 1021(1303-282)$ by a loss of 18:1-fatty acid substituent at $s n-1$, and to the ion at $\mathrm{m} / \mathrm{z}$ 965 that signifies that a 16:0-fatty acid substituent is attached to mannose 1.

The set of the ions at $m / z$ 1319, 1275, and 965 (Figure $4 \mathrm{~d})$, reflecting the 16:1-, 19:0-, and 16:0-fatty acyl moieties at $s n-2, s n-1$ and at mannose 1 , respectively, probably arises from a 16:0-19:0/16:1-PIM $\mathrm{PI}_{3}$ structure. The assignment is further confirmed by the $\mathrm{MS}^{3}$-spectra of the ions at $\mathrm{m} / \mathrm{z} 1275(1573 \rightarrow 1275)$ and at $\mathrm{m} / \mathrm{z} 1319$ $(1573 \rightarrow 1319)$ (shown in Supplementary Material). The spectra showed that the ions at $\mathrm{m} / \mathrm{z} 1319$ and 1275 are a $\left[\mathrm{M}-\mathrm{H}-\mathrm{R}_{2} \mathrm{CO}_{2} \mathrm{H}\right]^{-}$and a $\left[\mathrm{M}-\mathrm{H}-\mathrm{R}_{1} \mathrm{CO}_{2} \mathrm{H}\right]^{-}$ions, respectively. The IT $\mathrm{MS}^{3}$-spectrum of $\mathrm{m} / \mathrm{z} 1275$ is dominated by the ion at $m / z 1021(1275-254)$ arising from further loss of the 16:1-fatty acid at sn-2, along with the ion at $\mathrm{m} / \mathrm{z} 965$ that signifies the attachment of a 16:0fatty acid moiety to mannose 1 ; the IT MS ${ }^{3}$-spectrum of $\mathrm{m} / \mathrm{z} 1319$ is dominated by the ion at $\mathrm{m} / \mathrm{z} 1021$ (1319 298), from loss of the 19:0-fatty acid substituent at sn-1, along with the ion at $m / z 965$, consistent with the attachment of a 16:0-fatty acid moiety to mannose 1 . The combined information results in the assignment of the 16:0-19:0/16:1-PIM ${ }_{3}$ structure. Therefore, isomers with 16:0-19:1/16:0-PIM ${ }_{3}$ 17:0-18:1/16:0-PIM ${ }_{3}, 16: 1-19$ : 0/16:0-PIM ${ }_{3}$, 16:0-18:1/17:0-PIM ${ }_{3}$, and 16:0-19:0/16:1$\mathrm{PIM}_{3}$ structures can be assigned for the ion at $\mathrm{m} / \mathrm{z} 1573$.

Monoacyl-PIM ${ }_{4}$ and monoacyl-PIM ${ }_{6}$. The two ions belong to the monoacyl-PIM 4 family observed at $\mathrm{m} / \mathrm{z} 1738$ and 1722 were of low abundance and the ions corresponding to monoacyl-PIM ${ }_{5}$ were not observed (Figure 1c). The profile of the IT MS ${ }^{2}$-spectrum of the $\mathrm{m} / \mathrm{z} 1738$ ion (Figure 5a) is nearly identical to that observed for 16:0-19:0/16:0- $\mathrm{PIM}_{3}$ (Figure 4a) and the spectrum is dominated by the ions at $m / z 1481(1738.0-256.2)$ and 1439 (1738.0 - 298.3), indicating that the 16:0- and 19:0-fatty acyl substituents are located at $s n-2$ and $s n-1$, respectively. The ions arising from losses of the diacylglycerol and phosphatidylinositol moieties, respectively, are seen at $m / z 1127$, and 1047, while the ions arising from direct loss of the palmitoylmannosyl moiety are seen at $\mathrm{m} / \mathrm{z} 1337$ and 1319 . These ions are $162 \mathrm{Da}$ higher than the analogous ions observed in the $\mathrm{MS}^{2}$ spectrum of 16:0-19:0/16:0-PIM ${ }_{3}$, indicating that the ion at $m / z 1738$ is a $16: 0-19: 0 / 16: 0-\mathrm{PIM}_{4}$. The ions at $m / z 809$ and 791 may arise from further loss of the 16:0-fatty acyl substituent as a ketene and as an acid, respectively, from $m / z 1047(1738.0$ - 690.4), which arises from loss of a 19:0/16:0-PA moiety from $\mathrm{m} / \mathrm{z} 1738$. In contrast, the analogous ions at $m / z 647$ and 629 observed for 16:0-19:

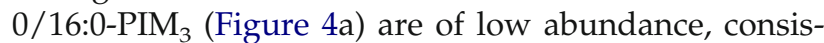
tent with the earlier findings that the abundances of the glycoside ions increase as the number of the hexose residue increases. The IT $\mathrm{MS}^{2}$-spectrum of the $\mathrm{m} / \mathrm{z} 1722$ ion (not shown) is also similar and represents a 16:0-18: 1/16:0-PIM 4 structure. 

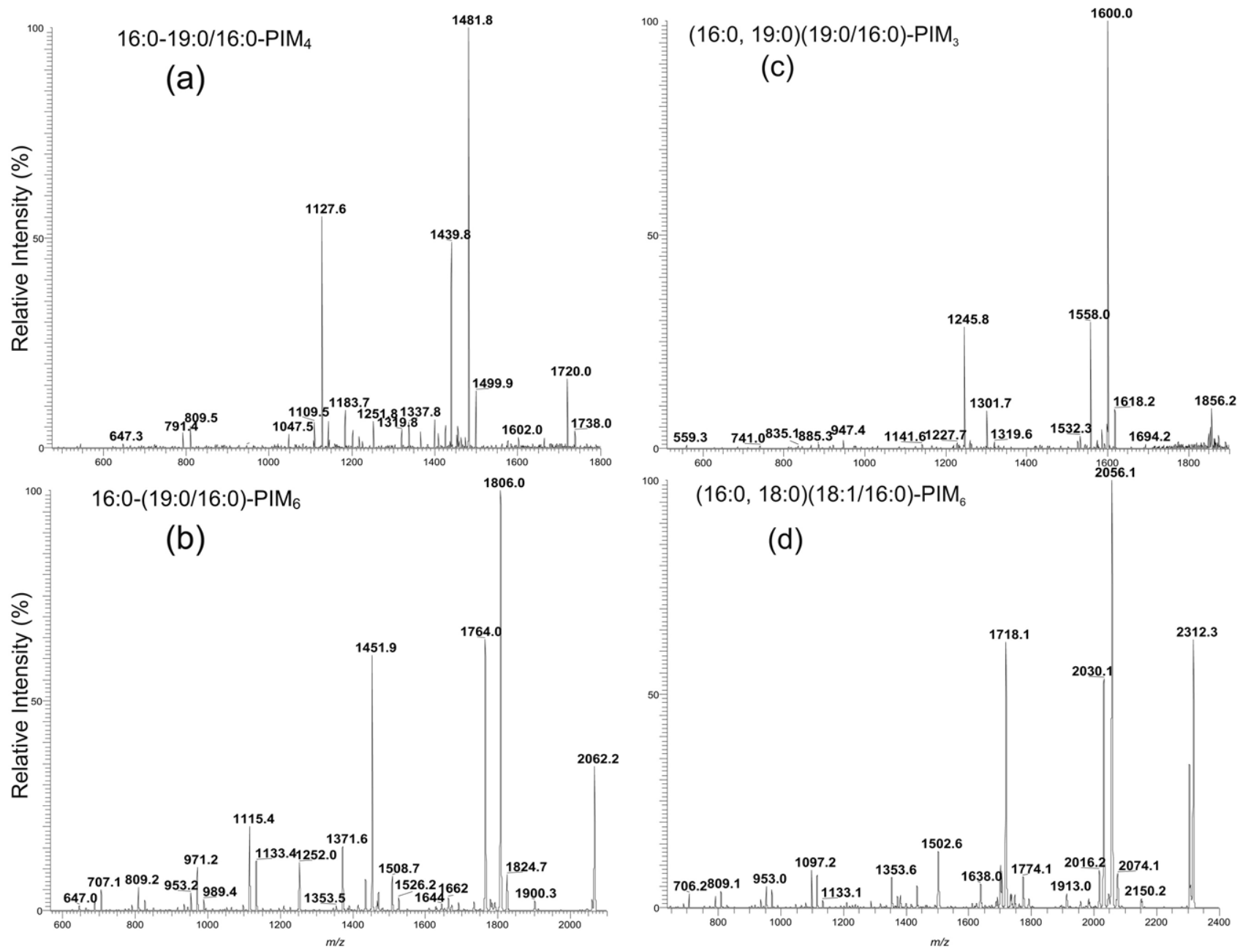

Figure 5. The IT MS ${ }^{2}$ product-ion spectra of the $[\mathrm{M}-\mathrm{H}]^{-}$ions of 16:0-19:0/16:0-PIM $\mathrm{P}_{4}$ at $\mathrm{m} / \mathrm{z} 1737$ $\left({ }^{*} \mathrm{~m} / \mathrm{z}\right.$ 1738.0) (a), of 16:0-(19:0/16:0)-PIM ${ }_{6}$ at $\mathrm{m} / \mathrm{z} 2061\left({ }^{*} \mathrm{~m} / \mathrm{z}\right.$ 2062.1) (b), of $(16: 0,19: 0)(19: 0 / 16: 0)-\mathrm{PIM}_{3}$ at $\mathrm{m} / \mathrm{z} 1855\left({ }^{*} \mathrm{~m} / \mathrm{z}\right.$ 1856.2) (c), and of $(16: 0,18: 0)(18: 1 / 16: 0)-\mathrm{PIM}_{6}$ at $\mathrm{m} / \mathrm{z} 2311\left({ }^{*} \mathrm{~m} / \mathrm{z} 2312.3\right)$. Asterisk = with mass defect.

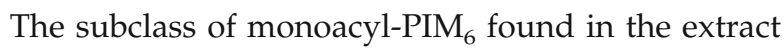
is among the more prominent in the monoacyl-PIM family. The major ions were observed at $\mathrm{m} / \mathrm{z} 2062$ and $\mathrm{m} / \mathrm{z} 2046$ (Figure 1e), representing a 16:0-(19:0/16:0)$\mathrm{PIM}_{6}$ and a 16:0-(18:1/16:0)-PIM ${ }_{6}$, respectively. The IT $\mathrm{MS}^{2}$-spectrum of the ion at $\mathrm{m} / \mathrm{z} 2062$ (Figure $5 \mathrm{~b}$ ) is dominated by the ions at $\mathrm{m} / \mathrm{z} 1806(2062.2-256.2)$ and 1764 (2062.2 - 298.3), arising from loss of the 16:0- and 19:0-fatty acid substituents at $s n-2$ and $s n-1$, respectively. The ions analogous to those observed for 16:019:0/16:0-PIM 4 were observed at $\mathrm{m} / \mathrm{z} 1451$ and 1371, arising from losses of the 19:0/16:0-glycerol and the 19:0/16:0-PA moieties, respectively, as well as the ions at $m / z 1115(1371-256)$ and $1133(1371-238)$ arising from $\mathrm{m} / \mathrm{z} 1371$ by further loss of the 16:0-fatty substituent as an acid and as a ketene, respectively. The above results indicate that the ion is a 16:0-(19:0/16:0)- $\mathrm{PIM}_{6}$. The prominence of the glycosyl ions at $\mathrm{m} / \mathrm{z} 1115$ and 1133 that possess an inositol and six mannose residues, again, is in agreement with the earlier notion that the glycosyl ions become more prominent as the number of the sugar residue increases. Similar results are also observed in the IT MS's-spectra of the ion at $\mathrm{m} / \mathrm{z} 2046$, $2020,2074,2090$, and at 2104 which represent a 16:0-(18: 1/16:0)-PIM ${ }_{6}$ 16:0-(16:0/16:0)-PIM ${ }_{6}$, a 18:0-18:1/16:0PIM $_{6}$, a 18:0-19:0/16:0-PIM 6 , and a 19:0-19:0/16:0-PIM 6 isomer, respectively (data not shown). These ions may consist of more than one isomer. However, the structural detail is not available from the present data due to the limited resolution of our ITMS instrument that fails to achieve unit mass resolution for a mass over $2000 \mathrm{Da}$. Thus, a composite $\mathrm{MS}^{\mathrm{n}}$ spectrum arising from a range of various precursor ions ( $>5 \mathrm{Da})$ resulted.

\section{Characterization of Diacyl-PIM Molecular Species}

Diacyl-PIM $_{2}$. The negative-ion ESI/MS profile of the $[\mathrm{M}-\mathrm{H}]^{-}$ions in the mass region corresponding to the diacyl-PIM ${ }_{2}$ as shown in Figure $1 \mathrm{~d}$ is dominated by the ions at $m / z 1678,1694$ and 1652. The $\mathrm{MS}^{2}$-spectrum of the $\mathrm{m} / \mathrm{z} 1678.1$ ion (Figure 6a) contains the major ions at $m / z 1421(1678.1$ - 256.2) and $1439(1678.1$ - 238.2) 

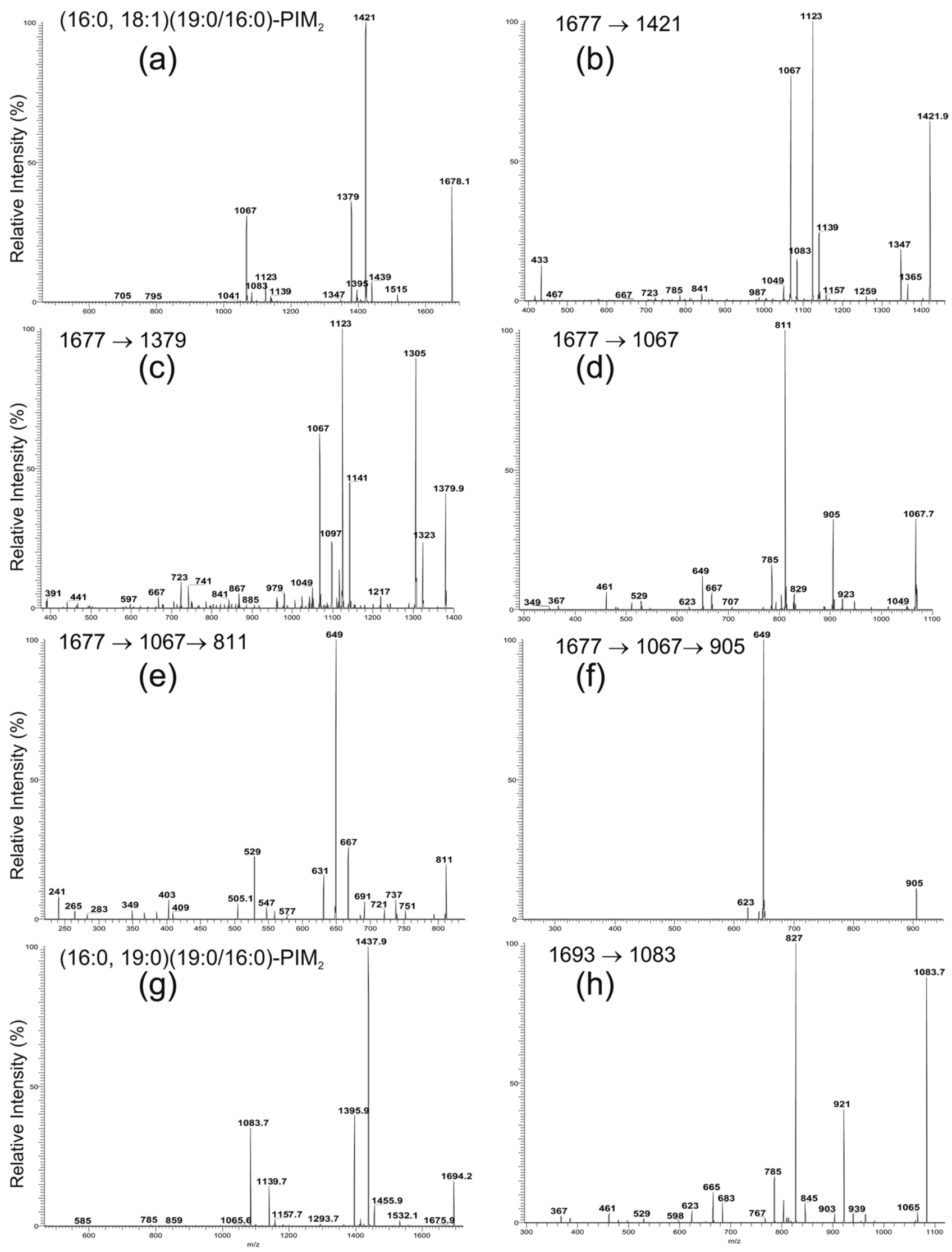

Figure 6. The IT MS ${ }^{2}$ product-ion spectrum of the $[\mathrm{M}-\mathrm{H}]^{-}$ions of $(16: 0,18: 1)(19: 0 / 16: 0)-\mathrm{PIM}_{2}$ at $1677\left({ }^{*} \mathrm{~m} / \mathrm{z} 1678.1\right)(\mathbf{a})$, and its $\mathrm{MS}^{3}$ product-ion spectra of the ions at $\mathrm{m} / \mathrm{z} 1421(1677 \rightarrow 1421)(\mathbf{b})$, at $\mathrm{m} / \mathrm{z}$ $1379(1677 \rightarrow 1379)(\mathbf{c})$, at $\mathrm{m} / z 1067(1677 \rightarrow 1061)(\mathbf{d})$, and its $\mathrm{MS}^{4}$ product-ion spectra at $\mathrm{m} / \mathrm{z} 811$ $(1677 \rightarrow 1067 \rightarrow 811)\left(\right.$ e) , and at $m / z 905\left(1677 \rightarrow 1067 \rightarrow\right.$ 905) $\left(\right.$ f). Panel $($ g) $)$ illustrates the MS $^{2}$-spectrum of the $(16: 0,19: 0)(19: 0 / 16: 0)-\mathrm{PIM}_{2}$ at $1693\left({ }^{*} \mathrm{~m} / \mathrm{z}\right.$ 1694.2) and its $\mathrm{MS}^{3}$-spectrum of the ion at $\mathrm{m} / \mathrm{z} 1083$ $(1693 \rightarrow 1083)(\mathrm{h})$. Asterisk $=$ with mass defect. 
arising from loss of the 16:0-fatty acyl substituent as an acid and as a ketene, respectively, and at $\mathrm{m} / \mathrm{z} 1379$ (1678.1 - 298.3) and 1397 (1678.1 - 280.3), arising from the analogous losses of the 19:0-fatty acyl substituent. The ions of the former set are respectively more abundant than the ions of the latter set, indicating that the 16:0- and 19:0-fatty acyl substituents are located at sn-2 and $s n-1$, respectively. The assignments are further confirmed by the $\mathrm{MS}^{3}$ product-ion spectra of the ions at $\mathrm{m} / \mathrm{z} 1421$ (Figure 6b) and 1379 (Figure 6c). The former spectrum contains ions at $m / z 1365(1421-56)$ and 1347 $(1421-74)$ with a profile that shows that the ion at $\mathrm{m} / \mathrm{z}$ 1421 is a $\left[\mathrm{M}-\mathrm{H}-\mathrm{R}_{2} \mathrm{CO}_{2} \mathrm{H}\right]^{-}$ion, while the latter spectrum contains ions at $m / z 1323(1379$ - 56) and 1305 $(1379$ - 74) with a profile that is consistent with the findings that the ion at $m / z 1379$ is a $[\mathrm{M}-\mathrm{H}-$ $\left.\mathrm{R}_{1} \mathrm{CO}_{2} \mathrm{H}\right]^{-}$ion, arising from loss of the 16:0-fatty acid substituent at $s n-1$ from $m / z 1678$.

The ion at $m / z 1067$ in Figure 6a arises from loss of 16:0/19:0-diacylglycerol and gives a $\mathrm{MS}^{3}$-spectrum $(1678 \rightarrow 1067)$ (Figure $6 \mathrm{~d}$ ) that contains a prominent ion at $m / z 811$ arising from loss of a 16:0-fatty acid substituent, probably attached to mannose 1 . This speculation is due to the fact that the profile of the spectrum is similar to that arising from $m / z 803$ (Figure 2d), an analogous ion that gives rise to a prominent ion at $m / z 547$ by loss of the 16:0-fatty acid substituent at mannose 1 . In contrast, the ion at $m / z 785$ arising from loss of the 18:1-fatty acyl substituent, probably at the inositol is of low abundance. These results may indicate that loss of the fatty acid substituent at mannose 1 is more facile than loss of the fatty acid substituent at the inositol.

Further dissociation of the ion at $\mathrm{m} / \mathrm{z} 811$ (1678 $\rightarrow 1067 \rightarrow 811$ ) (Figure 6e) leads to the prominent ion at $\mathrm{m} / \mathrm{z} 649$ by loss of a mannose residue, along with the ion at $m / z 529$ corresponding to loss of a 18:1-fatty acid substituent, probably at the inositol. The $\mathrm{MS}^{3}$-spectrum of the ion at $m / z 905(1678 \rightarrow 1067 \rightarrow 905)$ (Figure $6 f)$ is dominated by the ion at $m / z 649$, arising from further loss of the 16:0-fatty acid substituent. However, the ion at $m / z \quad 623$ arising from loss of an 18:1-fatty acid substituent is of low abundance. The results are consistent with the notion that loss of the 16:0-fatty acid substituent at mannose 1 is more facile than loss of the 18:1-fatty acid substituent at the inositol. The preferential loss of the fatty acyl substituent at mannose 1 over that at the inositol provides information to locate the position of fatty acid substituents in the glycoside.

In addition to the $(16: 0,18: 1)(19: 0 / 16: 0)-\mathrm{PIM}_{2}$ isomer as assigned above, the $m / z 1678$ ion may also consist of a $(16: 0,19: 0)(18: 1 / 16: 0)-\mathrm{PIM}_{2}$ isomer. This is based on the findings that the $\mathrm{MS}^{2}$-spectrum of $m / z 1678$ (Figure 6a) also contains the ions at $m / z 1395$ (1678.1 - 282.3), corresponding to loss of a 18:1-fatty acyl substituent, along with $\mathrm{m} / \mathrm{z} 1083$, which is identical to the phospholipoglycoside ion seen in the $\mathrm{MS}^{2}$-spectrum of $(16: 0$, 19:0)(19:0/16:0)- $\mathrm{PIM}_{2}$ (Figure 6g, discuss later). The presence of the $(16: 0,19: 0)(18: 1 / 16: 0)-\mathrm{PIM}_{2}$ structure is consistent with the fact that the MS ${ }^{3}$-spectrum of the ion at $m / z 1421$ (Figure 6b) also contains the ion at $m / z$ 1139, arising from further loss of the 18:1-fatty acid substituent at $s n-1$, and the phospholipoglycoside ion at $m / z$ 1083, which contains both a 16:0- and a 19:0-fatty acyl substituents.

The $\mathrm{MS}^{2}$-spectrum of the $m / z 1694.1$ (Figure $6 \mathrm{~g}$ ) is also dominated by the ions at $m / z 1437$ (1694.1 - 256.2) and 1395 (1694.1 - 298.3), arising from losses of the 16:0-, 19:0-fatty acid substituents, respectively. The profile is similar to that shown in Figure 6a, indicating that the 16:0- and 19:0-fatty acyl moieties are located at sn-2, and $s n-1$, respectively. The ions at $m / z 1531$ and 1083 arise from loss of a mannosyl residue and loss of the diacylglycerol moiety, respectively, while the ion at $\mathrm{m} / \mathrm{z}$ 1139 arises from the combined losses of the 16:0- and 19:0-fatty acid substituents. The identification of the fatty acid substituent attached to mannose 1 is recognized by the $\mathrm{MS}^{3}$-spectrum of the 1083 ion $(1693 \rightarrow$ 1083) (Figure 6h), which contains the prominent ion at $m / z$ 827, arising from loss of 16:0-fatty acid substituent. In contrast, the ion at $m / z 785$, reflecting loss of the 19:0-fatty acyl substituent at the inositol is less abundant. The results suggest that the ion at $\mathrm{m} / \mathrm{z} 1694$ represents a $(16: 0,19: 0)(19: 0 / 16: 0)-\mathrm{PIM}_{2}$ structure.

The complexities of the structures of the diacyl-PIM $\mathrm{P}_{2}$ in the extract as revealed by multiple-stage IT mass spectrometry (Table 1) are demonstrated by the structural assignment of the ion at $m / z$ 1676. The $\mathrm{MS}^{2}$ product-ion spectrum of the ion at $\mathrm{m} / \mathrm{z} 1676.1$ (Figure 7a) contains several sets of the fragment ions corresponding to losses of the 16:0-, 16:1-, 19:0-, 18:1-, 19:1-, and 17:0-fatty fatty acyl substituents as acids and as ketenes, respectively. These ions were seen in the sets of the ions at $m / z 1419$ and 1437; $m / z 1421$ and 1439; m/z 1377 and 1395; $\mathrm{m} / \mathrm{z} 1393$ and 1411; $\mathrm{m} / \mathrm{z} 1379$ and 1397; and at $\mathrm{m} / \mathrm{z}$ 1405 and 1423, respectively (Figure 7a, inset 1 ). The ions reflecting the losses of the various diacylglycerol residues from the various isomers were observed at $\mathrm{m} / \mathrm{z}$ $1067,1065,1083$, and 1081, respectively, consistent with the presence of the ions at $m / z 1121,1123,1137$, and 1139, respectively (Figure $7 \mathrm{a}$, inset 2), arising from the combined losses of the fatty acid substituents at $s n-1$ and at $s n-2$.

The major (16:0, 18:1)(19:0/16:1)- $\mathrm{PIM}_{2}$ structure is revealed by the IT $\mathrm{MS}^{3}$-spectrum of the $m / z 1419$ ion $(1675 \rightarrow 1419)$ (Figure $7 \mathrm{~b})$, arising from primary loss of a 16:0-fatty acid. The profile of the fragment ions at $\mathrm{m} / \mathrm{z}$ $1345(1419$ - 74) and $1363(1419$ - 56) confirms that the 16:0-fatty acid is located at $s n-2$, while the ions at $\mathrm{m} / \mathrm{z}$ 1137,1123 , and 1121, arising from losses of the 18:1-, 19:1-, and 19:0-fatty acyl substituents at sn-2, respectively, indicate that the isomers with 18:1/16:0-, 19:1/ 16:0-, and 19:0/16:0-glycerol moieties, respectively, are also present. The ions at 1137, 1123, and 1121 are respectively formed together with the ions at $m / z 1081$, 1067, and 1065, which represent the phospholipoglycoside ions that possess a (16:0, 19:1), (16:0,18:1), and $(16: 1,18: 1)$ fatty acyl substituents, residing at mannose 1 and inositol, respectively. The assignments of the fatty 

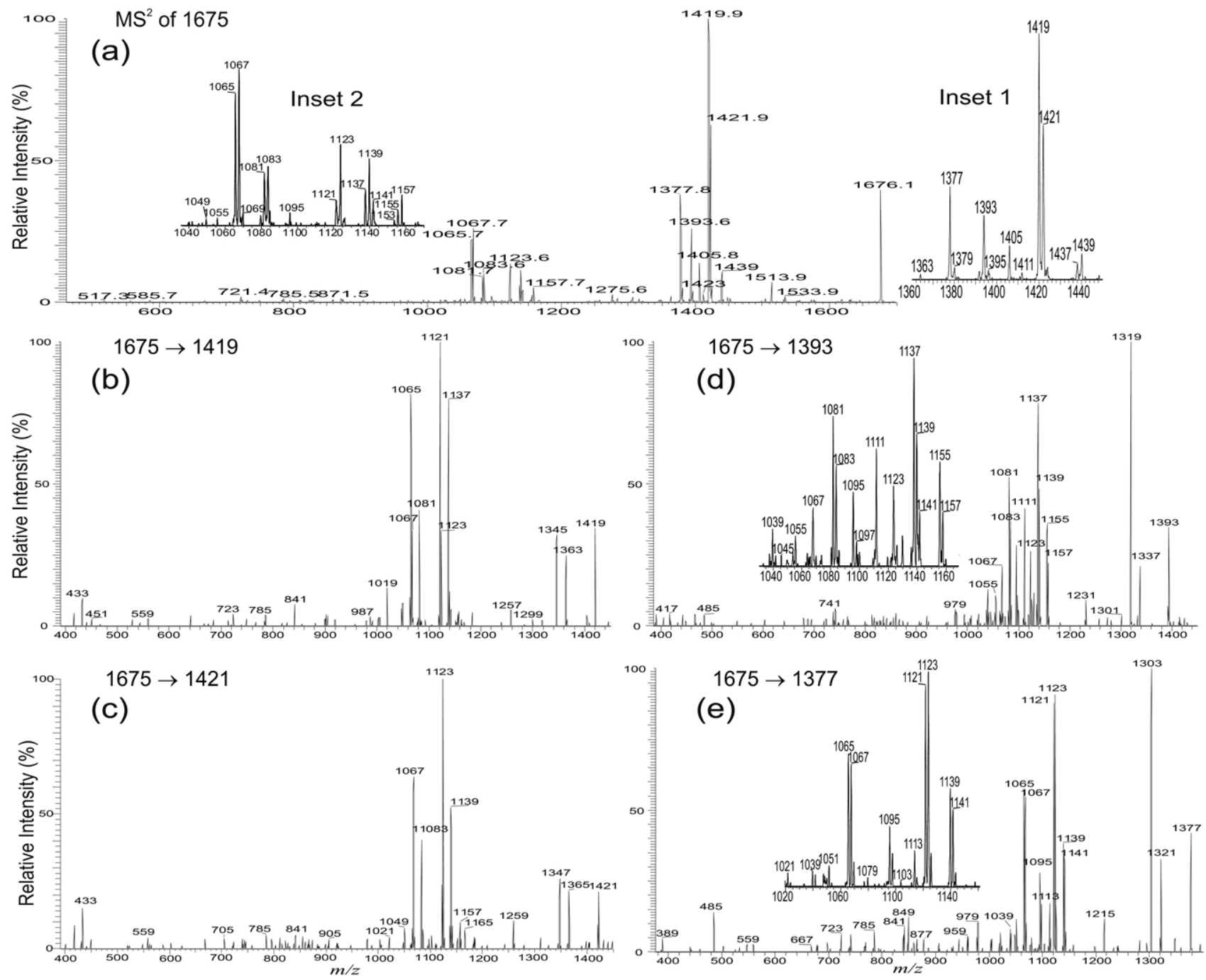

Figure 7. The IT MS ${ }^{2}$ product-ion spectrum of the $m / z 1675\left({ }^{*} m / z\right.$ 1676.1) ion (a), and its $\mathrm{MS}^{3}$ product-ion spectra of the ions at $m / z 1419(1675 \rightarrow 1419)(\mathbf{b})$, at $m / z 1421(1675 \rightarrow 1421)(\mathbf{c})$, at $\mathrm{m} / \mathrm{z} 1393$ $(1675 \rightarrow 1393)(\mathbf{d})$, at $m / z 1377(1675 \rightarrow 1377)(\mathbf{e})$. The combined information revealed that the ion is consisted of a major (16:0, 18:1)(19:0/16:1)-PIM 2 structure along with five minor isomers (see text for detail). Asterisk $=$ with mass defect.

acyl substituents at mannose 1 or at the inositol are further confirmed by the MS ${ }^{3}$-spectra of $m / z$ 1065, 1067, and 1081 (data not shown), which are similar to those observed earlier (Figure 6d and $\mathrm{h}$ ) and are consistent with the presence of $(16: 1,18: 1)(19: 0 / 16: 0)-\mathrm{PIM}_{2}$, (16:0, 18:1)(19:1/16:0)-PIM ${ }_{2}$, and (16:0, 19:1)(18:1/16:0)-PIM ${ }_{2}$ structures.

The profile of the IT $\mathrm{MS}^{3}$-spectrum of the ion at $\mathrm{m} / \mathrm{z}$ $1421(1675 \rightarrow 1421)$ (Figure 7c) is similar to that arising from the ion at $\mathrm{m} / \mathrm{z} 1419$ (Figure $7 \mathrm{~b}$ ), indicating that the $\mathrm{m} / \mathrm{z} 1421$ ion arises from $\mathrm{m} / \mathrm{z} 1675$ by loss of the 16:1-fatty acyl substituent at $s n-2$. The ion at $\mathrm{m} / \mathrm{z} 1123$ arising from further losses of a 19:0 -fatty acyl substituents at $s n-1$, is formed together with the ion at $m / z$ 1083, which represents a phospholipoglycoside anion that contains a 16:0-fatty acyl substituent at mannose 1 and a 19:0-fatty acyl substituent at inositol respectively, while the ion at $\mathrm{m} / \mathrm{z} 1139$, arising from loss of a 18:1-fatty acid substituent is formed together with the ion at $m / z 1067$, representing an analogous ion possessing a 16:0-fatty acyl substituent at mannose 1 and a 18:1-fatty acyl substituent at inositol. These results reveal the (16:0, 19:0)(18:1/16:1)-PIM ${ }_{2}$ and (16:0, 18:1) (19:0/16:1)-PIM 2 structures.

In contrast, the IT MS ${ }^{3}$-spectrum of the $\mathrm{m} / \mathrm{z} 1393$ ion $(1675 \rightarrow 1393)$ (Figure $7 d$ ), arising from primary loss of a 18:1-fatty acid contains ions at $\mathrm{m} / \mathrm{z} 1319(1393-74)$ and $1337(1393$ - 56) with the feature that shows that the ion at $\mathrm{m} / \mathrm{z} 1393$ originates from loss of a 18:1-fatty acid at $s n-1$ from 1675 . The sets of ions reflecting losses of the 16:0- (ions at $\mathrm{m} / \mathrm{z} 1137$ and 1155), 16:1- (ions at $\mathrm{m} / \mathrm{z}$ 1139 and 1157), 18:1- (ions at $m / z 1111$ and 1129), and 17:0-fatty acid substituents (ions at $\mathrm{m} / \mathrm{z} 1123$ and 1141) as acids and ketenes, respectively, are also observed in the spectrum, indicating the presence of the isomers with (18:1/16:0)-, (18:1/16:1)-, (18:1/18:1)-, and (18:1/ 
17:0)-glycerol residues. These ions are formed concurrently with the ions at $m / z$ 1081, 1083, 1055, and 1067, respectively, which are the phospholipoglycoside anions containing $(16: 0,19: 1),(16: 0,19: 0),(16: 0,17: 0)$, and $(16: 0,18: 1)$ fatty acyl substituents at mannose 1 and inositol, respectively. The results lead to the assignments of the two major $(16: 0,19: 1)(18: 1 / 16: 0)-\mathrm{PIM}_{2}$ and $(16: 0,19: 0)(18: 1 / 16: 1)-\mathrm{PIM}_{2}$ structures, as well as the two minor (16:0, 17:0)(18:1/18:1)-PIM 2 and (16:0, 18: 1)(18:1/17:0)-PIM ${ }_{2}$ species. The structures of $(16: 0,19$ : 1)(18:1/16:0)-PIM 2 and (16:0, 19:0)(18:1/16:1)-PIM $\mathrm{P}_{2}$ revealed here are consistent with those resulting from the $\mathrm{MS}^{3}$-spectra of $\mathrm{m} / \mathrm{z} 1419$ and 1421 as shown earlier.

The profile of the IT $\mathrm{MS}^{3}$-spectrum of the $\mathrm{m} / \mathrm{z} 1377$ ion $(1675 \rightarrow 1377)$ (Figure 7 e) is similar to that observed for the $m / z 1393$ ion, indicating that the ion at $m / z 1377$ arises from $m / z 1675$ via further elimination of the 19:0-fatty acyl substituent at sn-1. Again, the ions formed from the loss of the 16:0-fatty acyl substituents at $s n-2$ as an acid and as a ketene are observed at $m / z$ 1121 and 1139, respectively, while the ion pairs from the analogous losses of the 16:1- and 18:1-fatty acyl substituents are seen at $m / z 1123(1377-254)$ and 1141 (1377 - 236), and at $m / z 1095$ (1377 - 282) and 1113 (1377 - 264), respectively. These ions are formed together with the ions at $m / z$ 1065, 1067 and 1039 that represent the phospholipoglycosides possessing a (16:1, $18: 1),(16: 0,18: 1)$, and a $(16: 0,16: 1)$-fatty acyl substituents, respectively. Therefore, isomers with (16:1, 18: 1)(19:0/16:0)-PIM ${ }_{2}$, (16:0, 18:1)(19:0/16:1)-PIM ${ }_{2}$, and (16:0, 16:1)(19:0/18:1)-PIM 2 structures can be deduced. The assignments of the $(16: 1,18: 1)(19: 0 / 16: 0)-\mathrm{PIM}_{2}$ and $(16: 0,18: 1)(19: 0 / 16: 1)-\mathrm{PIM}_{2}$ structures are consistent with the results deduced from the $\mathrm{MS}^{3}$-spectra of $\mathrm{m} / \mathrm{z}$ 1419 and 1421.

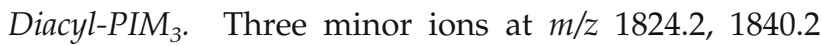
and 1856.2 arising from diacyl-PIM ${ }_{3}$ were observed (Figure 1e). The IT MS ${ }^{2}$-spectrum of the $\mathrm{m} / \mathrm{z} 1856.2$ ion (Figure 5c) contains the analogous ions as seen for (16:0, 19:0)(19:0/16:0)-PIM $\mathrm{PM}_{2}$ at $\mathrm{m} / \mathrm{z} 1694$ (Figure 6g). The ions at $m / z 1600$ (1856.2 - 256.2) and 1558 (1856.2 - 298.3) arise from losses of the 16:0-fatty acyl substituent at $s n-2$ and the 19:0-fatty acyl substituent at $s n-1$, respectively. The ion at $m / z 1245$, arising from loss of the 19:0/16:0diacylglycerol moiety is 162 Da higher than the analogous ion at $m / z 1083$ as shown in Figure 6g, indicating that the ion consists of a $(16: 0,19: 0)(19: 0 / 16: 0)-\mathrm{PIM}_{3}$ structure. This is consistent with the presence of the ion at $m / z 1532(1856$ - 324), arising from loss of a dimannosyl residue. Similar $\mathrm{MS}^{2}$ product-ion spectra were also observed for the ions at $m / z 1824$ and 1840 (not shown), arising from a (16:0, 18:1)(18:1/16:0)-PIM 3 and a $(16: 0,18: 1)(19: 0 / 16: 0)-\mathrm{PIM}_{3}$ structures, respectively.

Diacyl-PIM ${ }_{6}$. The ions corresponding to diacyl-PIM $\mathrm{M}_{4}$ and diacyl-PIM ${ }_{5}$ were not observed, but the species from diacyl-PIM 6 are abundant (Figure 1e). The structural characterization is exemplified by the ion at $\mathrm{m} / \mathrm{z}$
2312.3, which gives the IT $\mathrm{MS}^{2}$-spectrum (Figure 5d) that is dominated by the ion at $\mathrm{m} / \mathrm{z} 2056$ (2312.3 256.2), arising from loss of the 16:0-fatty acid substituent at $s n-2$, along with the ions at $\mathrm{m} / \mathrm{z} 2030$ (2312.3 282.3), arising from loss of the 18:1-fatty acid substituent at $s n-1$. The results suggested that the compound probably consists of a (18:1/16:0)-glycerol backbone, consistent with the observation of the ion at $m / z 1718$, arising from $\mathrm{m} / \mathrm{z} 2312$ by loss of the $(18: 1 / 16: 0)$ diacylglycerol residue. The observation of the ion at $\mathrm{m} / \mathrm{z}$ $1502(2312-162 \times 5)$ arising from loss of a pentamannosyl chain, indicates that the molecule is a diacylPIM $_{6}$. The recognition of the 16:0-fatty acid situated at $s n-2$ is further confirmed by the $\mathrm{MS}^{3}$-spectrum of the ion at $m / z 2056(2312 \rightarrow 2056)$ (data not shown), which contains the ions at $\mathrm{m} / \mathrm{z} 1982(2056-74)$ and 2000 (2056 - 56) with a profile that shows the $m / z 2056$ ion is indeed a product-ion of $m / z 2312$ from loss of the 16:0-fatty acid substituent at $s n-2$.

Further dissociation of the ion at $\mathrm{m} / \mathrm{z} 1718$ (shown in Supplementary Material) gives rise to the ion at $\mathrm{m} / \mathrm{z}$ 1462, arising from loss of the 16:0-fatty acid substituent attached to mannose 1 . The ions at $\mathrm{m} / \mathrm{z} 1556$ (1718 162), 1394 (1718 - $2 \times 162), 1232$ (1718 - $162 \times 3), 1069$ $(1718-162 \times 4)$, and $907(1718-162 \times 5)$, arise from losses of the various polymannosides linked to the 2-O-inositol, respectively. The results are consistent with the notion that the molecule is a diacyl-PIM . The observation of the ion at $m / z 1317$ (1718 - 400.4) arising from loss of the palmitoylmannosyl residue attached to 6-O-inositol is also consistent with the fact that a 16:0-fatty acid substituent is attached to mannose 1 . The $\mathrm{MS}^{4}$-spectrum of the ion at $\mathrm{m} / z 1317(2312 \rightarrow 1718 \rightarrow$ 1317) (data not shown) gives a prominent ion at $\mathrm{m} / \mathrm{z}$ 1033 (1317 - 284) by further loss of the 18:0-fatty acid substituent, indicating that a 18:0-fatty acid substituent is attached to the inositol. The above information suggests that the ion at $m / z 2312$ is mainly a $(16: 0,18: 0)(18: 1 / 16: 0)-P_{6}$.

The characterization of the diacyl-PIM ${ }_{6}$ s that consist of multiple isomeric structures is not conclusive, again, owing to the limitation of our current ion-trap instrument that is unable to specifically select the precursor ions that are greater than 2000 Da as described earlier.

\section{Conclusions}

The present method clearly demonstrates that multiplestage ion-trap mass spectrometry with ESI is readily applicable for structural characterization of phosphatidylinositol-mannosides, including monoacyl- and diacylPIMs, as well as PI and PIMs that were described earlier [2]. Although this approach provides neither the information applicable for establishing the linkage of the fatty acid substituent to the glycoside in monoacyl-PIMs (i.e., to the O-6 position of the O-2 linked Manp), nor the information that establishes the linkage of the additional fatty acid substituent to the C3 position of the myo-inositol for diacyl-PIMs, the assignment of the fatty acid substituents 
attached to the 2-O-linked Manp, the myo-inositol, and to the glycerol backbone that are located at $s n-1$ or $s n-2$ can be easily achieved. More importantly, the structures of the molecular species that consist of various isomers can be revealed in detail, using the present approach. However, the implementation of an ion-trap instrument with sufficient resolution for selecting the high $\mathrm{m} / \mathrm{z}$ precursor ions, such as those from diacyl-PIM $\mathrm{P}_{6} \mathrm{~s}$, is necessary for their unambiguous structural assignment.

\section{Acknowledgments}

This research was supported by US Public Health Service Grants P41-RR-00,954, R37-DK-34,388, P60-DK-20,579, and P01-HL-57,278 and P30-DK56341.

\section{References}

1. Yague, G.; Segovia, M.; Valero-Guillen, P. L. Phospholipid Composition of Several Clinically Relevant Corynebacterium Species as Determined by Mass Spectrometry: An Unusual Fatty Acyl Moiety is Present in Inositol-Containing Phospholipids of Corynebacterium urealyticum. Microbiology 2003, 149, 1675-1685.

2. Hsu, F. F.; Turk J.; Owens, R.; Rhoades, E. R.; Russell, D. G. Structural Characterization of Phosphatidylinositol Mannosides from Mycobacterium bovis BCG by Multiple-Stage Quadrupole Ion-Trap Mass Spectrometry with Electrospray Ionization. I. PIMs and Lyso-PIMs. I. Am. Soc. Mass Spectrom. 2007, 18, 466-478.

3. Khoo, K. H.; Dell A.; Morris, H. R.; Brennan, P. J.; Chatterjee, D. Structural Definition of Acylated Phosphatidylinositol Mannosides from Mycobacterium tuberculosis: Definition of a Common Anchor for Lipomannan and Lipoarabinomannan. Glycobiology 1995, 5, 117-127.

4. Gilleron, M.; Bala, L.; Brando, T.; Vercellone, A.; Puzo, G. Mycobacterium tuberculosis H37Rv Parietal and Cellular Lipoarabinomannans: Characterization of the Acyl- and Glycoforms. J. Biol. Chem. 2000, 275, 677-684.

5. Gilleron, M.; Ronet, C.; Mempel, M.; Monsarrat, B.; Gachelin, G.; Puzo, G. Acylation State of the Phosphatidylinositol Monnosides from Mycobacterium bovis Bacillus Calmette Guérin and Ability to Induce Granuloma and Recruit Natural Killer T Cells. J. Biol. Chem. 2001, 276, 34896-34904.

6. Gilleron, M.; Quesniaux, V. F. J.; Puzo, G. Acylation State of the Phosphatidylinositol Hexammanosides from Mycobacterium bovis Bacillus Calmette Guérin and Mycobaterium tuberculosis H37Rv and Its Implication in Toll-Like Receptor Response. J. Biol. Chem. 2003, 278, 2988029889

7. Nigou, J.; Gilleron, M.; Brando, T.; Puzo, G. Structural Analysis of Mycobacterial Lipoglycans. Appl. Biochem. Biotechnol. 2004, 118, 253-268.

8. Nigou, J.; Gilleron, M.; Puzo, G. Lipoarabinomannans: Characterization of the Multiacylated Forms of the Phosphatidyl-Myo-Inositol Anchor by NMR Spectroscopy. Biochem. J. 1999, 337, 453-460. 